\title{
DECONVOLUTION OF SUPERPOSED POLE FIGURES BY DISCRETE ODF METHODS: COMPARISON OF ADC AND WIMV FOR QUARTZ AND CALCITE WITH TRIGONAL CRYSTAL AND TRICLINIC SPECIMEN SYMMETRY
}

\author{
H. R. WENK \\ Department of Geology and Geophysics, University of California, \\ Berkeley, CA 94720 \\ K. PAWLIK AND J. POSPIECH \\ Institute of Metals Research, Polish Academy of Sciences, Reymonta 25, \\ Krakow, Poland \\ J. S. KALLEND \\ Department of Metallurgical and Materials Engineering, \\ Illinois Institute of Technology, Chicago, IL 60616
}

(Received 11 February 1994; Received in final form 22 March 1994)

\begin{abstract}
Discrete methods of orientation distribution (ODF) analysis are applied to quartz and calcite rocks with trigonol crystal and triclinic sample symmetry. ODF's are calculated from pole figures measured by neutron diffraction. A particular complication for quartz is the presence of overlapping peaks which can be separated with the WIMV or ADC algorithms based on diffraction intensity differences. Both methods provide similar solutions. Characteristic differences are discussed. By comparing ODF's obtained from different data subsets (changing number and extent of pole figures) it is concluded that quantity and quality of data, as well as the texture type, have a crucial influence on resolution. It is demonstrated that discrete methods provide the possibility to obtain quantitative texture information from minimal experimental data.
\end{abstract}

KEY WORDS: ODF calculation, ADC method, WIMV method, superposed pole figures, estimation of errors, quartz, calcite.

\section{INTRODUCTION}

Quartz was the first mineral for which a three dimensional orientation distribution (ODF) was determined from X-ray pole figure data (Baker et al., 1969). The original incentive was to use the ODF to determine $c$-axis pole figures, which cannot be measured directly with X-rays, from measured pole figures of other lattice directions. In fine-grained aggregates of quartz $c$-axes were not accessible to conventional optical analysis with 
the universal stage on a petrographic microscope, yet the $c$-axis distribution of important diagnostic value. The ODF analysis has provided much more information than merely $c$-axis pole figures. ODF's represent a full description of the texture and have become indispensable for the interpretation of deformation and recrystallization textures.

Quartz is a challenging case for ODF analysis and poses various complications. The point group symmetry is 32 , which is enantiomorphic, and polycrystals may exist in both left handed and right handed forms with different orientation distributions. Very little is known about this: using optical measurements, Wenk (1985) illustrated that quartzites consist of different fractions of right handed and left handed crystals and that the two may have different orientation distributions. In several quartzites piezoelectric measurements suggest that there is indeed a difference between orientation distribution of left and right handed crystals (e.g., Bishop, 1981, Ghomshei and Templeton, 1989 Ivankina et al., 1991).

To describe the full texture of quartz, two ODF's are necessary for representation, one for right handed and one for left handed crystals. Unfortunately, the special optical methods which can distinguish between left and right handed quartz are rarely applicable, and enantiomorphism cannot be resolved with standard diffraction techniques. Therefore, quartz is treated in this paper as if it were centrosymmetric. Adding a symmetry center to point group 32 (Figure 1a) changes it to $\overline{3} 2 / \mathrm{m}$ which is the point group of calcite (Figure $1 \mathrm{~b}$ ). In point group $\overline{3} 2 / \mathrm{m}$ lattice planes such as rhombs $101(r)$ and $011(z)$ are not equivalent and diffract with different intensity (Figure 2a). (In this paper we are using 3-index diffraction indices hkl rather than 4-index Miller Bravais indices hkil with $i=-(h+k)$.) However, they have the same $d$-spacing and diffract at the same $2 \theta$ angle, contributing to a single diffraction peak. Positive rhombs (h0l) and negative rhombs (Ohl) may have different pole distributions but contrary to left handed and right handed crystals which have independent orientation distributions, pole figures of positive and negative forms have to be compatible with the same ODF. This trigonal ODF can be derived by making use of the intensity differences of positive and negative forms which contribute to a diffraction peak. The diffraction intensities from a single crystal or from a random powder depend on the crystal structure and can be accurately calculated for X-ray or neutron diffraction. Table 1 gives a list of a relative neutron and X-ray diffraction intensities for the lattice planes used in this study.

The method of deconvolution of overlapping pole figures based on known relative intensity contributions has been applied to quartz textures by various investigators. Baker and Wenk (1972), Bunge and Wenk (1977), Jura et al. (1978), Schmid and Casey (1986) used the harmonic method. A limiting factor of the harmonic method is the degree of expansion $\left(l_{\max }\right)$ which restricts the resolution $\left(\operatorname{Res} \approx 360^{\circ} /\left(\sqrt{2} l_{\text {max }}\right)\right.$, Matthies, 1980, Prospiech, 1988a, b). In order to obtain a resolution of $5^{\circ}$ in the ODF, which is the standard grid, one would have to extend the expansion to $l \approx 50$. In the case of trigonal crystal symmetry this would require to use about 16 pole figures which can not be readily achieved unless an iterative harmonic method is applied (Dahms, 1993).

The problem of obtaining the ODF from overlapped pole figures can also be approached with discrete methods which are sometimes called direct methods because they solve the problem directly in ODF space and not, as in the harmonic method, in reciprocal (Fourier) space (e.g. Kallend et al., 1991). The resolution restriction does not appear in the same rigorous form in discrete methods as in the harmonic method. Direct methods have been criticized for being too complicated, time-consuming and very sensitive to experimental errors. With new developments in software and computer 


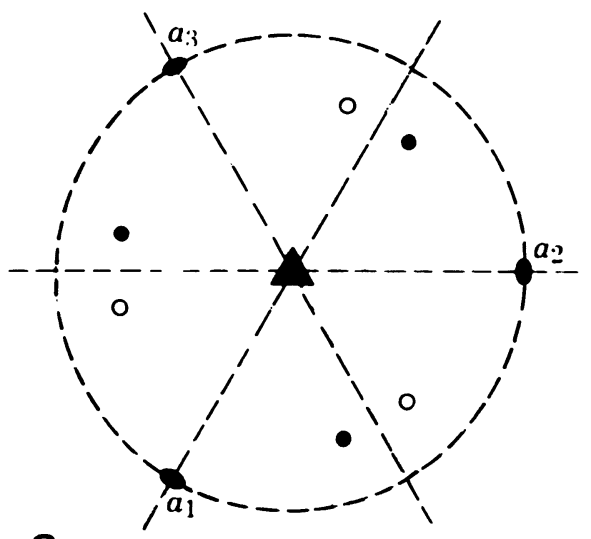

a

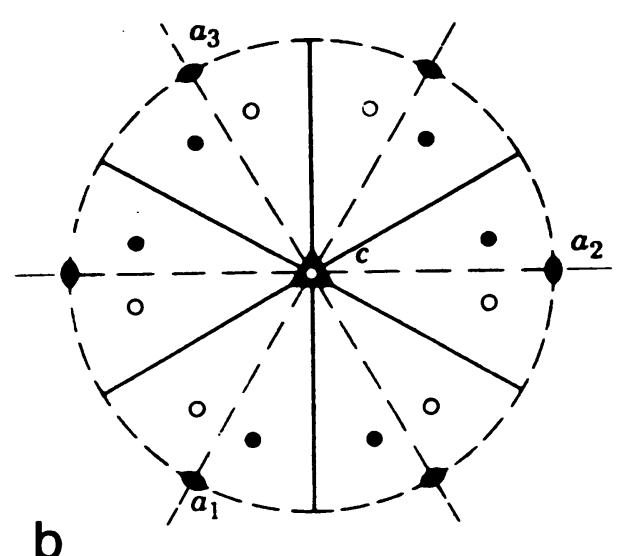

Figure 1 Stereographic projection with symmetry elements and crystal coordinate system a) pointgroup 32 (quartz), b) pointgroup $32 / \mathrm{m}$ (calcite).

hardware this is no longer true. In this paper we demonstrate advantages and limitations of direct methods for two typical quartzite textures using the WIMV (acronym for Williams, Imhof, Matthies, Vinel) algorithm (Matthies, 1982) and the related ADC (acronym for Arbitrarily Defined Cells) method (Pawlik and Pospiech, 1986). We add, for comparison, an analysis of catcite which is also trigonal but due to the systematic extinctions in the rhombohedral spacegroup $R \overline{3} c$ there are no superpositions. In the case of calcite either positive or negative forms contribute to a diffraction peak (Table 2).

In all three examples complete pole figures were measured by neutron diffraction. We will investigate how the number of pole figures, the type of pole figures, and the ùsed pole figure range in incomplete pole figures influences the resolution of the ODF.

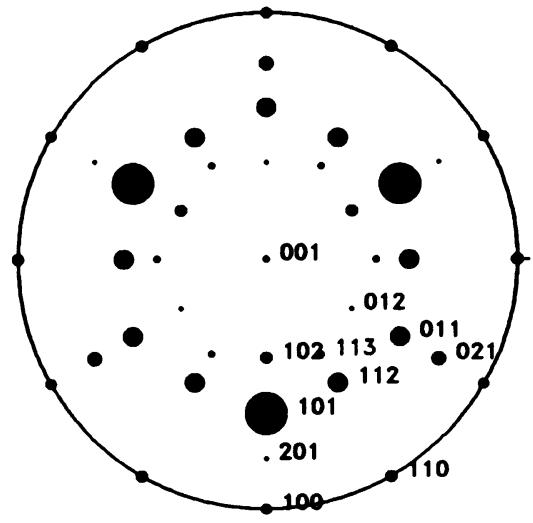

a

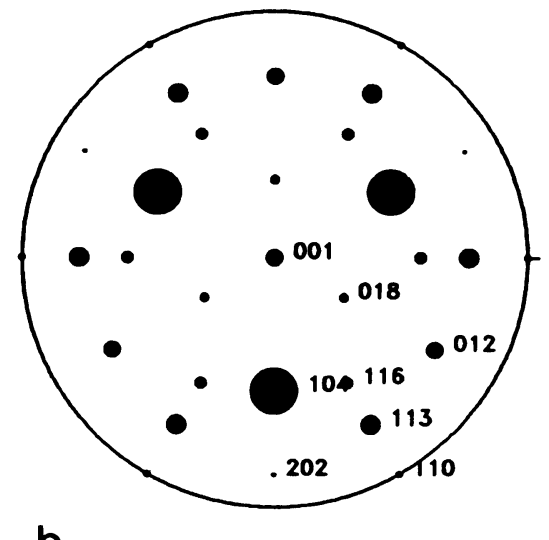

b

Figure 2 Equal area projection of poles used in the ODF analysis of (a) quartz and (b) calcite. Size of dots is proportional to the neutron diffraction intensity. 
Table 1 Calculated diffraction intensities hkil of quartz used in this study. Normalized for $10 \overline{1} 1=100$.

\begin{tabular}{ccccc}
\hline$h k i l$ & $h k l$ & $d(\AA)$ & neutron & $X$-ray \\
\hline $10 \overline{1} 0$ & 100 & 4.25 & 21 & 28 \\
$11 \overline{2} 0$ & 110 & 2.46 & 26 & 11 \\
$11 \overline{2} 2$ & 112 & 1.82 & 43 & 19 \\
$11 \overline{2} 3$ & 113 & 1.45 & 11 & 3 \\
$20 \overline{2} 11$ & 201 & 1.98 & 3 & 1.4 \\
$02 \overline{2} 11$ & 021 & 1.98 & 27 & 3.3 \\
$10 \overline{1} 1$ & 101 & 3.34 & 100 & 100 \\
$01 \overline{1} 1$ & 011 & 3.34 & 40 & 44 \\
$10 \overline{1} 2$ & 102 & 2.28 & 27 & 1.5 \\
$01 \overline{1} 2$ & 012 & 2.28 & 4 & 8.9 \\
\hline
\end{tabular}

In the past, similar tests have been done with idealized standard functions (e.g. Matthies et al., 1988, Pawlik et al., 1986, 1991, 1992). Using real data illustrates new limitations due to small errors in the data sets. Also we will demonstrate that limitations in the ODF resolution are much more serious for low symmetries than for cubic/ orthorhombic ones. We will show with experimental quartz and catcite data that discrete methods works equally well for real data with weak diffraction intensity and low symmetry, pushing resolution to the limits.

This paper deals with methodological issues of texture analysis. The physical significance of the observed textures and an attempt to explain texture development as a result of geological deformation processes will be the content of a separate study.

\section{SAMPLES AND EXPERIMENTAL DETAILS}

Two samples chosen for this study are metamorphic quartzites from the Bergell Alps in SE Switzerland. A preliminary survey with the petrographic microscope revealed strong preferred orientation. The two samples were selected from a series of quartzites

Table 2 Calculated diffraction intensities hkil of calcite used in this study. Normalized for $10 \overline{1} 4=100$.

\begin{tabular}{ccccc}
\hline hkil & $h k l$ & $d(\AA)$ & neutron & $X$-ray \\
\hline 0006 & 006 & 2.85 & 33 & 2.1 \\
$11 \overline{2} 0$ & 110 & 2.50 & 9 & 16 \\
$11 \overline{2} 3$ & 113 & 2.29 & 42 & 15 \\
$11 \overline{2} 6$ & 116 & 1.88 & 7 & 17 \\
$20 \overline{2} 2$ & 202 & 2.10 & 2.3 & 15 \\
$10 \overline{1} 4$ & 104 & 3.04 & 100 & 100 \\
$01 \overline{1} 2$ & 012 & 3.86 & 34 & 3.8 \\
$01 \overline{1} 8$ & 018 & 1.91 & 14 & 17 \\
\hline
\end{tabular}


which are being investigated to characterize texture development of quartz during deformation and recrystallization and are representative of two very common texture types. Brg 420 from Caccior (Promontogno) is a muscovite-bearing quartzite band in gneisses at the transition of greenschist to amphibolite facies metamorphic grade. Quartz is coarse grained $(0.5-1 \mathrm{~mm})$ with serrated grain boundaries indicative of dynamic recrystallization by boundary migration. The texture is characterized by an asymmetric concentration of c-axes in a double maximum more or less in the schistosity plane and normal to the lineation, as is typical of many mylonite textures (e.g. Schmid and Casey, 1986, Sander, 1950, Mancktelow, 1987). Sci 490 from Albigna (Vicosoprano) is a quartzite layer with strongly flattened grains with undulatory extinction at an oblique angle to the compositional schistosity plane. Included muscovite "fish" are asymmetric and characteristic of SC (schistosité/cisaillement) structures (Berthé et al., 1979) in a shear regime. The sample was collected near the contact of the Tertiary Bergell granite, and deformation is attributed to the emplacement of the granite. The texture type is an asymmetric small circle of c-axes with an axis normal to the schistosity place (e.g. Trommsdorff and Wenk, 1963). Both samples have also been analyzed with the component method (Helming et al., 1994) and Brg 420 was also investigated with the SEM-EBSP technique (Kunze et al., 1994).

Pole figures of the two quartzites were measured on cubes with rounded corners and $12 \mathrm{~mm}$ edges by neutron diffraction $(\lambda=1.202 \AA)$ with a position sensitive detector at KFA Jülich, Germany. Experimental details have been described by Schäfer et al. (1992). Ten experimental pole figures were extracted by profile analysis on 700 sample orientations and seven pole figures were used in the ODF calculations. They were chosen such that lattice planes covered different orientations (Figure 2a) and also so that specific positive and negative rhombs have distinctly different diffraction intensities. Measured pole figures are shown in Figure 4 (top) after normalization to express densities in multiples of a random distribution (m.r.d.).

The calcite sample is an experimentally deformed limestone of nearly orthorhombic sample symmetry consistent with the plane strain/pure shear deformation geometry. It served as a "round robin" for a neutron diffraction standard project (Wenk, 1991). The data set used in this study is that measured at ILL, Grenoble, also with monochromatic neutrons $(\lambda=2.522 \AA)$ and a position sensitive detector. Eight pole figures of fairly regularly distributed lattice planes are used (Figure $2 b$ ). The measured calcite pole figures are shown in Figure 4c.

These pole figures served as input data for subsequent ODF analysis which was done with FORTRAN programs running under DOS on IBM compatible personal computers. WIMV programs were compiled with Lahey EM32, making use of the extended memory capability for large arrays; ADC programs were compiled with Microsoft Fortran version 5.0. Calculations for one sample took from 5 minutes for WIMV (with 20 iterations) to 5-15 minutes for $\mathrm{ADC}$ with a $33 \mathrm{MHz} 486$ processor. The time of computation depends on algorithm, compiler and the number of iteration cycles.

\section{ODF CALCULATION}

A pole figure is the projection of the ODF along lines in orientation space that corresponds to rotations of $2 \pi$ about the scattering vector. Pole figures are experimentally accessible, but not the ODF, unless individual crystal orientations are measured. The problem of texture analysis is to determine the three-dimensional ODF from a set of 
two-dimensional experimental pole figures, i.e. to obtain an approximation of the ODF from its projections. There are two different sources for ambiguity. Mathematically the relationship between pole figures and the ODF is described by an underdetermined system of equations. A trigonal/triclinic ODF, which is covered with a $5^{\circ}$ grid, consists in the discrete description of $19 \times 72 \times 24=33832$ numbers, in most cases far more than the number of data points in the measured pole figures which constitute the number of equations (e.g. $19 \times 72=1368$ for one complete pole figure, or $19 \times 72 \times n$ for $n$ complete pole figures). Additional complications arise due the presence of a center of symmetry in the pole figure data but not in the ODF. This causes an intrinsic rank deficiency which can also be viewed as a loss of uniqueness in pole figure correlations for polycrystalline distributions. It leads to an inherent ambiguity which causes that a unique ODF cannot be obtained. Instead a range of ODF solutions exists that fit the experimental pole figure data equally well. The ambiguity is clearly recognized when the harmonic method is used (Matthies, 1979). An ODF requires an expansion with even and odd spherical harmonics. If only even functions are used the resulting ODF is noisier with additional maxima and possibly negative areas. These falsifications are due to the missing odd part of the expansion of the ODF and are called "ghosts".

Considering of additional conditions can help to minimize the range of possible solutions - for example, an ODF can not be negative and zero values at any location on a pole figure must correspond to zero values in all orientations that contribute to that pole figure location. Different attempts have been made to solve the problem of ambiquity. Concepts for improving the harmonic method have been introduced (e.g. Bunge, 1982, Van Houtte, 1980). But most importantly these difficulties focused interest on discrete methods, which were less popular earlier because of their complex formalism. The discrete methods of ODF calculation from pole figures were developed early on by Williams (1968), advanced by Ruer and Baro (1977) and above all by Imhof (1978, 1982). Improved variants have been elaborated such as WIMV (Matthies and Vinel, 1982), ADC (Pawlik and Pospiech, 1986), and maximum entropy (Schaeben, 1988 and Wang, 1988, 1989). Below we outline some of the basic principles for direct methods and discuss similarities and differences between WIMV and ADC.

In approximating the ODF from pole figures these methods use projection lines through which information from pole figures is transferred into the orientation space. Both the pole figures and the ODF are represented as discrete functions. Whereas the procedures in the Williams and WIMV methods use projection lines (Figure 3b, c), the ADC method applies projection tubes which are adjusted to the size of the area elements of the pole figure hemisphere (Figure 3a). Values of the experimental pole figures are introducted into the cells of the orientation space by applying criteria of conformability of pole figures (experimental and recalculated) and also additional conditions. The approximation of the ODF proceeds by iterations. The conformability criterion for pole figures is not sufficient to obtain a unique solution because of the underdetermination and the inversion ambiguity. The aim of additional conditions is to supress possible falsifying ghost effects.

In the direct methods the non-negativity of the ODF, the assumption that a set of random pole figures or a single random pole figure give a random ODF and also that any zero in the pole figures leads to zeros in all corresponding ODF cells, are taken into account. In the WIMV as well as in the ADC algorithm of the ODF approximation, iterative procedures based on Imhof's concept are used, but there are some differences. It should also be mentioned that the necessary number of experimental pole figures, and the range of incomplete pole figures used in the discrete methods to obtain a good 

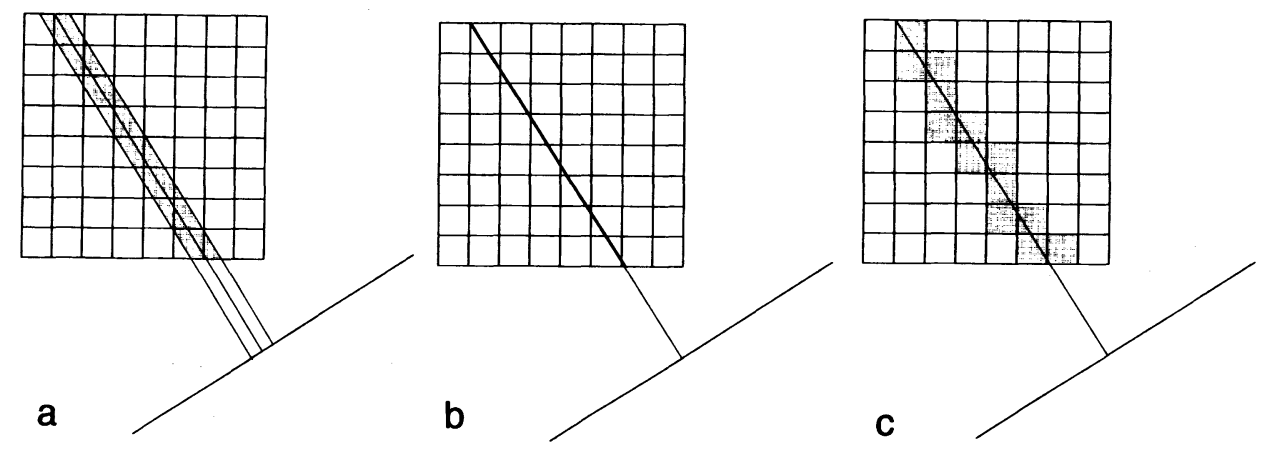

Figure 3 Schematic two-dimensional diagram illustrating pole figures as projection of ODF with projection lines and tubes. (a) ADC with projection tubes covering space uniformly, (b) Matthies WIMV weighing cells according to the length of the projection line, (c) popLA WIMV with all cells cut by the line given equal weight.

fit for the calculated pole figure, is - in principle - not as strongly restricted as in the harmonic method. Of course the minimum pole density set criterion (MPDS, Vadon, 1981) needs to be satisfied but this may not be sufficient.

The WIMV algorithm, in its must simple form, operates as follows: A set of pointers is established that relates each ODF cell with the cells on the pole figures to which it contributes diffracted intensity. An initial estimate of the ODF $f_{0}(g)$ is computed by placing in each ODF cell a value that is the geometric mean of the values in the associated pole figure cells. Following the notation of Matthies and Vinel (1982) it is expressed by

$$
f_{0}(g)=\prod_{i=1}^{I}\left(\prod_{m_{i}=1}^{M_{i}} P_{h_{i}}^{\exp }\left(Y_{m_{i}}\right)\right)^{1 / / M_{i}}
$$

Here $P_{h_{i}}$ is the pole density of the pole $h_{i}$ for the sample direction $Y_{m_{i}}, I$ is the total number of pole figures available, and $M_{i}$ is the number of crystal symmetry-related poles of the type $h_{i}$.

From the estimated ODF it is a simple task to compute the pole figures that it would generate. These recomputed pole figures will not, in general, agree very closely with the actual experimental data, and the discrepancies are used to improve the estimate of the ODF. The correction factor for each ODF value is the ratio of the geometric means of the corresponding experimental pole figure values to the geometric means of the corresponding recalculated pole figure values. The $(n+1)$ th estimate is then derived from the the $n$-th according to:

$$
f_{n+1}(g)=f_{n}(g) \frac{f_{0}(g)}{\prod_{i=1}^{I}\left(\prod_{m_{i}=1}^{M_{i}} P_{h_{i}}^{n}\left(Y_{m_{i}}\right)\right)^{1 / 1 M_{i}}}
$$

If, for example, the initial ODF estimate in a cell is too large, then the corresponding recalculated values for pole figure cells will also be too large, and the correction factor 
will be less than unity. This process is repeated until the discrepancy between the recalculated and actual pole figure data is below an acceptable threshold.

Optionally, the correction factor can be raised to a power $(>1)$ to speed convergence, but in the case of strong textures (if the power is not controlled by the algorithm) this can lead to undesirable oscillations in the solution.

In detail, different procedures have been taken. A simplified version of the WIMV method, which is used here, is implemented in the program package POPLA (Kallend et al., 1991). It contains the "inner iteration" of the WIMV method by Matthies and Vinel (1982). In the POPLA WIMV all ODF cells through which a projection line passes are weighed equally (Figure $3 \mathrm{a}$ ). In a refined version of WIMV, cells are weighed accordingly to the length of the line within a cell (Figure $3 b$ ).

The solution which is obtained has no negative regions and emphasizes large peaks but may still contain subsidiary "ghost" errors. Further constraints on the solution can be added, most commonly to limit the minimum value of the computed ODF. This is controlled in WIMV by a second iteration cycle ("outer iteration") to raise the background ("phon") as high as possible, thereby integrating the ghost intensities into the background. Whether this is physically justified or not can be argued (Matthies, 1990).

In the ADC method all details of geometrical relations between the hemisphere of the pole figure and the ODF space are more elaborate and assume a clearly arranged form. The concept of a set of integral equations with constant functional values in ODF or pole figure cells in WIMV is replaced in ADC by a system of linear algebraic equations. The correspondence between the projection tubes and ODF cells is done by taking into account the volume fraction of ODF cells contributing to the tubes. Projection tubes from each complete pole figure cover the. whole volume of the ODF (Figure 3c). The iteration process is composed of three cycles controlled by convergence measures.

In the first cycle ("I"), which provides a first approximation, an adjustment of experimental pole figures (" $i$ ") is performed by averaging of the deviations between measured and recalculated pole figures. This is achieved by an averaging operator of the following form (the outer brackets indicate averaging)

$$
{ }_{i} f_{a}^{(1)}=\left\langle\left\langle\left[\sum_{T_{k i e} \mid C_{a}} U_{a k i e} P_{k i e}^{\exp }\right]\right\rangle_{e=1, E_{i}}\right\rangle_{i=1, I}
$$

and

$$
{ }_{1} f_{\mathrm{a}}^{(n+1)}={ }_{I} f_{a}^{(n)}\left\langle\left\langle\left[\sum_{T_{k i e} \mid C_{a}} U_{a k i e} \frac{P_{k i e}^{\exp }}{{ }_{I} P_{k i e}^{(n)}}\right]\right\rangle_{e=1, E_{i}}\right\rangle_{i=1, I}
$$

Here $f_{a}$ is the value of the ODF assigned to the cell $C_{a}$ and $e$ gives numbers of symmetrical poles on the hemisphere of the $i$-th pole figure. $T_{k i e} \mid C_{a}$ denotes that summation proceeds along those tubes which intersect the cell $C_{a}, U_{a k i e}$ is the volume fraction of the part of the cell intersected by the tube.

A second cycle ("II") enforces the condition

$$
{ }_{I I} f_{a}^{(1)}=\min _{i, e}\left[\sum_{T_{k i e} \mid C_{a}} U_{a k i e}{ }_{\text {II }} P_{k i e}\right] \Rightarrow i=i_{m}, e=e_{m}
$$


where ${ }_{\text {II }} P_{k i e}={ }_{I} P_{k i e^{-}}^{(n)}$ According to this condition the values of the orientation density $f_{a}$ ascribed to each individual cell $C_{a}$ (in ODF space) is proportional to the smallest value of the projections of the hemispheres of all used pole figures. The obtained results are indicated by the indices $i=i_{m}$ and $e=e_{m}$. After normalization, pole figures ${ }_{I I} P_{k i e}$ are calculated and the value $Q_{I I}^{(n)}$ for $i=i_{m}$ and $e=e_{m}$.

$$
Q_{I I}^{(n)}=\left[\sum_{T_{k i e} \mid C_{a}} U_{a k i e} \frac{{ }_{I I} P_{k i e}}{P_{k i e}^{(n)}}\right]_{e=e_{m}, i=i_{m}}
$$

This condition (Eq 5), proposed first by Imhof (1978), is based on a property of orientation projections. Introduced in the iteration procedure, it allows to select the "true" components of the ODF through a pressure on densities from above which is introduced in the following iteration procedure:

$$
{ }_{I I} f_{a}^{(n+1)}=\left\{\begin{array}{lll}
{ }_{I I} f_{a}^{(n)} & \text { if } & Q_{I I}^{(n)} \geq 1 \\
{ }_{I I} f_{a}^{(n)} Q_{I I}^{(n)} & \text { if } & Q_{I I}^{(n)}<1
\end{array}\right.
$$

This eliminates remaining ghosts but adds their density to the peaks as well as to the isotropic background. In a final cycle of ADC ("III") results from the previous two cycles are adjusted by using the following operator:

$$
\begin{aligned}
& { }_{\text {III }} P_{\text {kie }}={ }_{\text {II }} P_{\text {kie }}^{(n)} \\
& { }_{\text {III }} f_{a}^{(1)}= \begin{cases}{ }_{I} f_{a}^{(n)} & \text { for }{ }_{I I} f_{a}^{(n)} \geq 1 \\
{ }_{I I} f_{a}^{(n)} & \text { for }{ }_{I I} f_{a}^{(n)}<1\end{cases} \\
& { }_{I I I} f_{a}^{(n+1)}=\left\{\begin{array}{lll}
{ }_{I I I} f_{a}^{(n)} Q_{I I I}^{(n)} & \text { if } \quad{ }_{I I I} f_{a}^{(n)} \geq 1 \\
{ }_{I I I} f_{a}^{(n)} & \text { if }{ }_{I I I} f_{a}^{(n)}<1
\end{array}\right.
\end{aligned}
$$

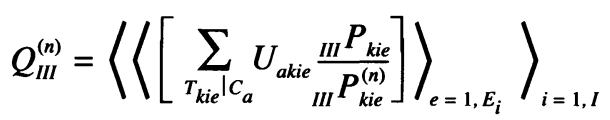

After each iteration step in each stage the ODF and pole figures are normalized.

The algorithms of the WIMV as well as of the ADC method, in its full formulation, are not capable of handling superposed pole figures which may occur among others in experimental data. This situation occurs frequently in low symmetry crystals where the $d$-spacings (and resultant $2 \theta$ values) are too close to be resolved in a texture diffractometer, and also in crystals such as trigonal quartz where symmetrically not equivalent lattice planes (e.g. positive and negative rhombs) have the same $d$-spacing.

We have modified the iteration algorithm to handle the case where the measured pole figure is a superposition of two or more different pole figures. The value $\boldsymbol{P}_{\text {kie }}$ measured in any domain (cell) at coordinates $\alpha, \beta$ will be the sum of contributions from each of the forms $P_{k i j e}$ weighted according to the weight factor $F_{i j}$ for each form and normalized in the usual manner,

$$
w_{i j}=\frac{F_{i j}}{\sum_{j=1}^{J} F_{i j}}
$$


However, given the ODF, it is a simple task to calculate any individual or superposed pole figure

$$
P_{k i e}=\sum_{j=1}^{J} w_{i j} P_{k i j e}
$$

The initial estimate of the ODF is made by assigning a weight $w_{i j}$ to each contributing form.

For non-superimposed forms, $w_{i j}=1$, and for superimposed forms $\sum_{j=1}^{J} w_{i j}=1$. The initial value in an ODF cell is set to the mean of the values for all corresponding cells from all contributing forms

$$
f_{a}^{(1)}=\left\langle\sum_{j=1}^{J} w_{i j}\left\langle\left[\sum_{T_{k j e} \mid C_{a}} U_{a k i j e} P_{k i e}\right]\right\rangle_{e=1, E_{i j}}\right\rangle_{i=1, I}
$$

This estimate will contain some undesirable cross coupling of the data from the superimposed pole figures.

The estimated ODF is used to make recalculated pole figures as before, with those corresponding to superimposed forms calculated according to eq (14). Correction factors for each ODF cell are now computed so that

$$
f_{a}^{(n+1)}=f_{a}^{(n)}\left\langle\sum_{j=1}^{J} w_{i j}\left\langle\left[\sum_{T_{k j e} \mid C_{a}} U_{a k j e} \frac{P_{k i e}}{P_{k i e}^{(n)}}\right]\right\rangle_{e=1, E_{i j}}\right\rangle_{i=1, I}
$$

Since eq (13) is an exact relationship used to compute pole figures, successive iterations will reduce the cross coupling introduced in the original estimate $f_{a}^{(1)}$. Essentially, each iteration drives the solution in the direction that improves the fit with the experimental data.

The rate of convergence of this procedure depends sensitively on the weight factors of the various contributing forms. In particular, if the weight factors are equal, then a wide range of possible solutions may fit the experimental data equally well. In this case, separation of the contributions from different forms to superimposed pole figures is dependent solely on the availability of other information in the data that will narrow the range of possible solutions. On the other hand, if the weight factors are very different, then convergence is rapid.

The weights $w_{i j}$ used in eq (13-15) are taken to be proportional to the intensity or squared structure factor for the various reflections.

With the quartz textures we will push the methods to their limits to determine how the quality and quantity of experimental data influence the ODF resolution. In this context it is important to discuss the minimum number of pole figures and pole figure ranges which are necessary to determine the ODF. In our case, for trigonal symmetry, an orientation is defined by two directions, e.g., 100 and 001 . To define an ODF value, it is necessary that projection lines of three $h k l$ poles intersect in any ODF cell. This has been originally discussed by Vadon (1981) and more recently by Helming (1991). We have calculated the number of equivalent poles ("legs") for incomplete reflection pole figures in the case of up to 7 quartz pole figures (Tables 3 and 4) and up to 8 calcite pole figures (Table 5). Three hkl intersections in each cell are necessary minimum requirement but generally not sufficient to determine the ODF. 
Textures are represented as pole figures and ODF's in equal area projection and contoured to show quantitative orientation densities. ODF's are in oblique $\sigma=$ $(\alpha+\gamma) / 2$ sections (Helming et al., 1987, Matthies et al., 1990 a, b) with minimal distortions.

We also use the texture index defined by Bunge (1982)

$$
J=\sum_{a}\left(f\left(g_{a}\right)\right)^{2} \Delta g_{a}
$$

where $f\left(g_{a}\right)$ is the value of the ODF belonging to the $j$-th cell of the orientation space. This bulk parameter describes some aspects of various models more compactly.

\section{RESULTS}

We will use a first quartzite sample Brg 420 to compare results of ODF calculations with the ADC and the WIMV algorithm for different sets of input data. Figure 5 illustrates ODF's in oblique sections. Figure 6 displays some recalculated pole figures $(112,113$, and 102 are not shown) and Figure 7 shows separated pole figures for positive and negative rhombs. Of the many examples which we tested we illustrate the following cases: All 7 complete pole figures, 2 complete pole figures $(110+101)$ and 7 pole figures used to $70^{\circ}$. We will first discuss ODF results (Figure 5). A general comment is that contours of the WIMV plot are more rugged than those of the ADC methods. This is a consequence of the integration algorithm which uses discrete cells rather than space-filling tubes. The ruggedness can be eliminated by a postprocessing filtering cycle after which WIMV and ADC results look almost indistinquishable. The unweighted discrete cell integration popLA WIMV has not much influence if many input data are used but becomes critical if input data are close to the limiting $h k l$ intersection criterion or in some cases when the number of pole figures is low. Sharp spikes can occur but usually they disappear during smoothing with a gaussian filter. The main features of all ODF's in Figure 5 are similar. Reducing the number of input pole figures from 7 to 2 has no significant effect on the ODF. However, changing the measured pole figure range from complete $\left(90^{\circ}\right)$ to $70^{\circ}$ is more detrimental. Note the appearance of an additional arc, visible in the $\sigma=20^{\circ}$ section (Figure 5 e-f). Naturally with fewer pole figure data, averaging is less complete and, with small errors in the data, there is more chance for deviations in individual cells creating small peaks which were not present in Figure 5a, b but in Figure 5 e, f. With fewer data contours become more rugged but interestingly maxima remain almost unchanged (Table 3 which also gives data for a $110+101<80^{\circ}$ reconstruction not shown in Figure 5), illustrating that many of the differences are more cosmetic than real.

Figure 6 shows pole figures for the same data sets as those illustrated in Figure 5. Corresponding experimental pole figures are shown in Figure 4a. Even more so than ODF's, pole figures are strikingly similar and there are no visible deviations in the regions which have been measured. Not only contour shapes but also actual minima and maxima are practically identical (Table 3). Consider, for example, that only 110 and 101 have been used in the calculation of the 8 pole figures in Figure $6 c$, d. Also in the recalculated pole figures there is some residual noise in WIMV, particularly visible in the center of the pole figures where weighing is most critical. Most of this noise disappears during smoothing (not shown). 


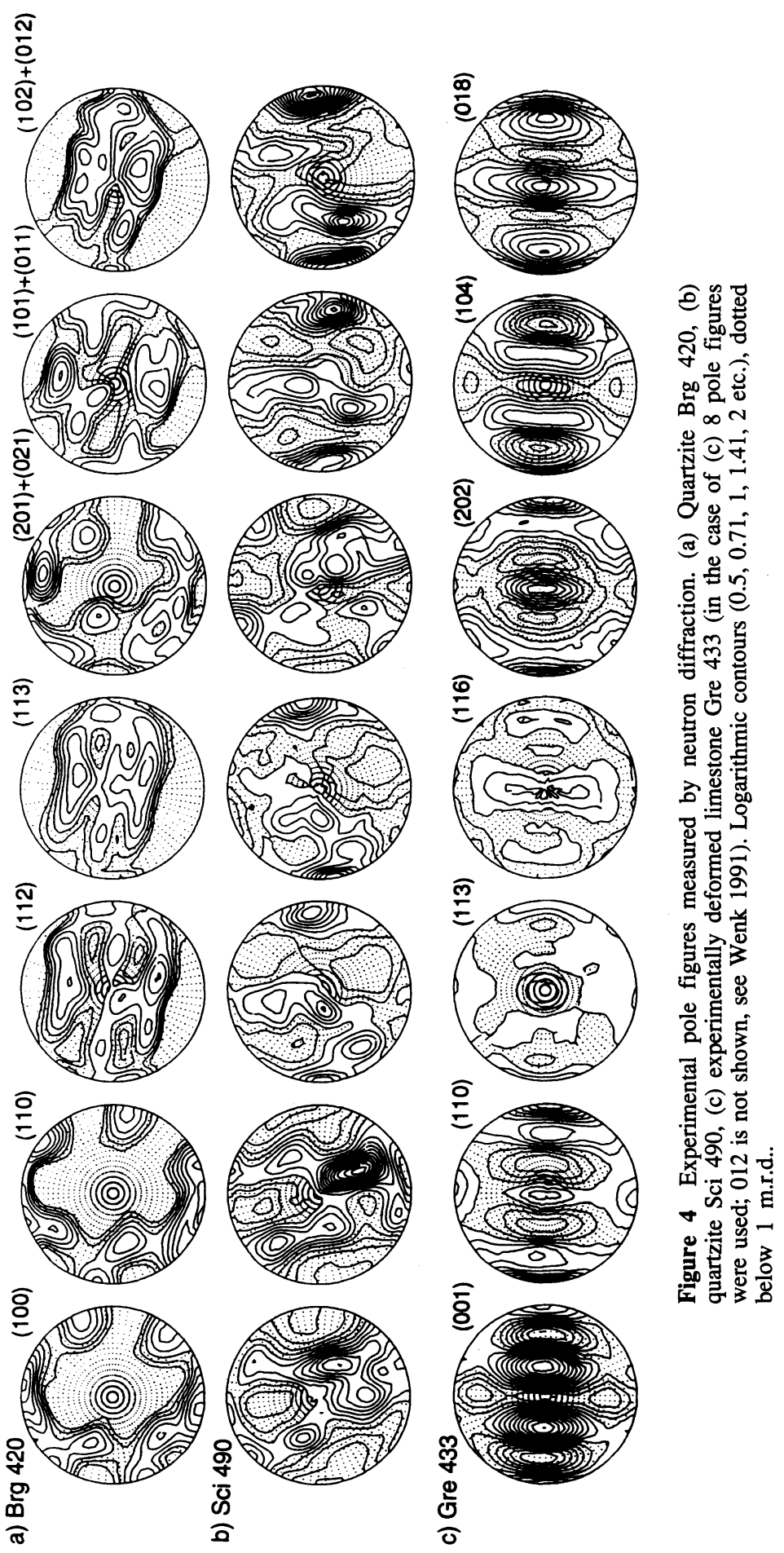


a) ADC

$7 \mathrm{pf}$

b) WIMV

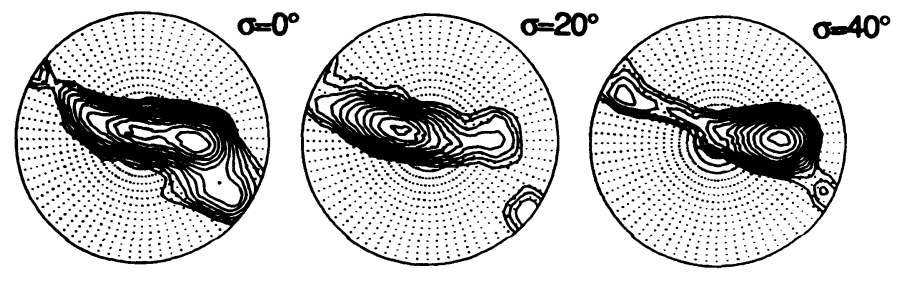

c) $A D C$
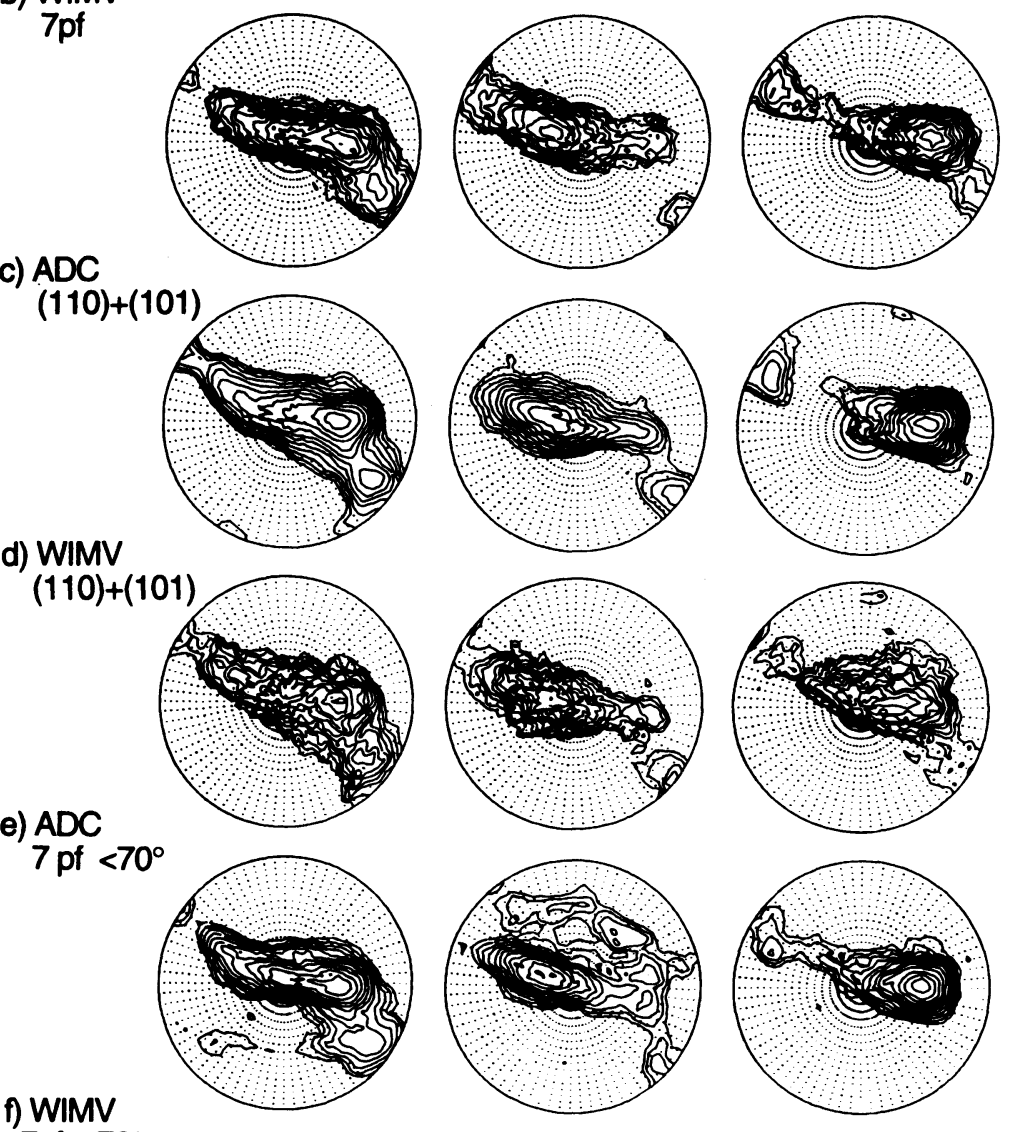

$7 \mathrm{pf}<70^{\circ}$
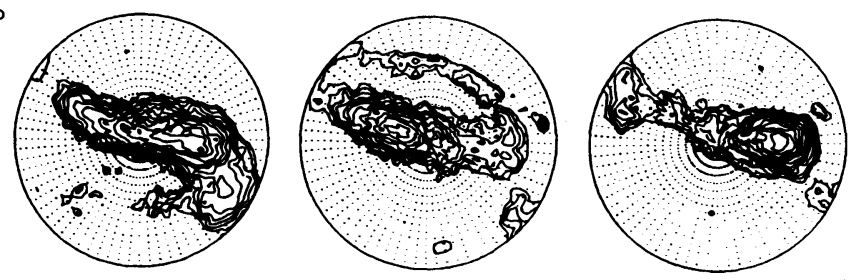

Figure 5 ODFs for quartzite $\mathrm{Brg} 420$, calculated from different data sets as indicated. Represented as $\sigma$-sections in equal area projection. Logarithmic contours $(0.5,0.71,1,1.41,2$ etc.), dotted below 1 m.r.d.. 


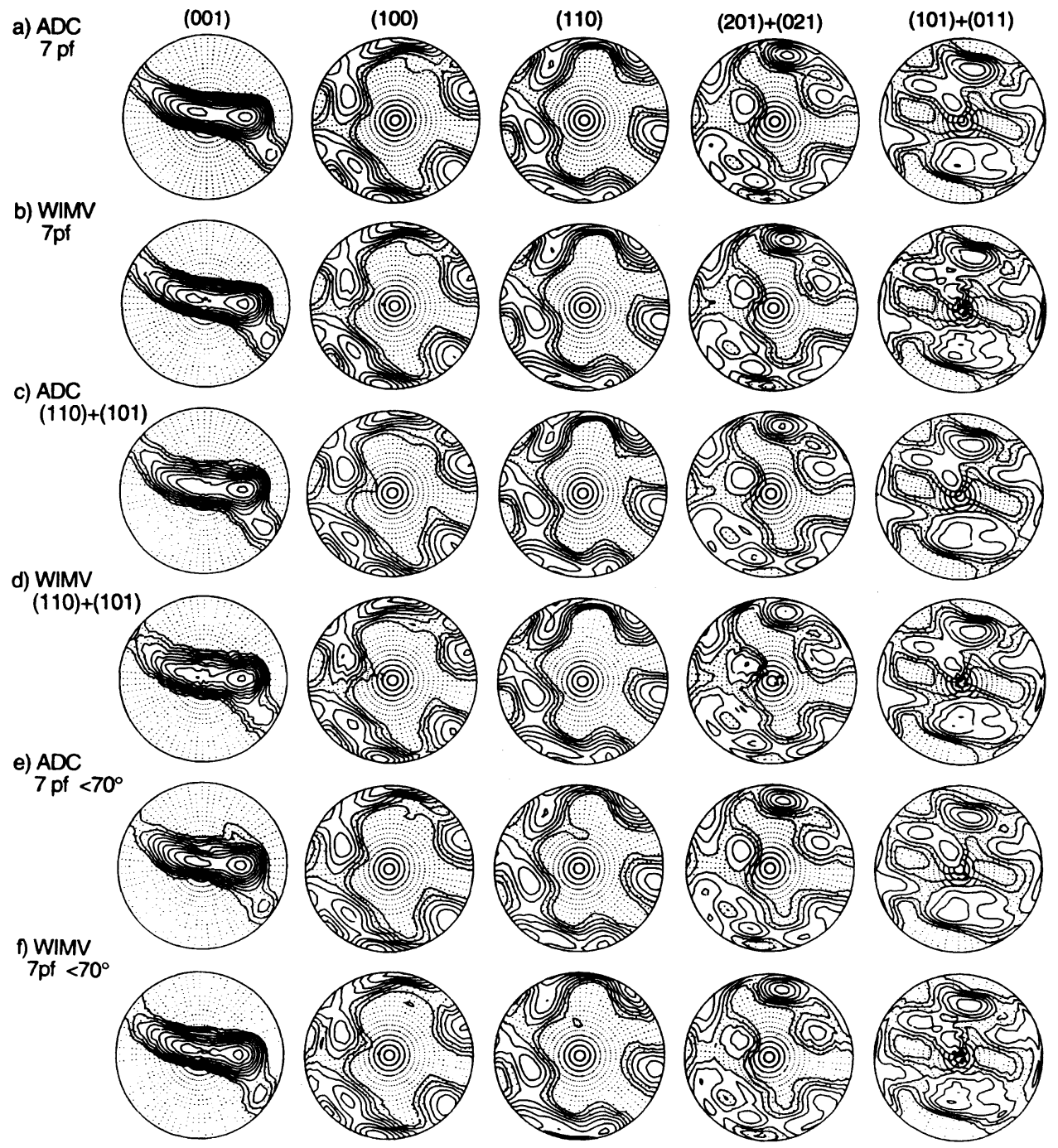

Figure 6 Pole figures of quartzite Brg 420, recalculated from the ODF for different models as indicated. Pole figures 112,113 and 102 which were used in some of the reconstructions are not shown. Logarithmic contours $(0.5,0.71,1,1.41,2$ etc.), dotted below 1 m.r.d..

A more critical test is the resolution of trigonal symmetry which, in the case of quartz, requires separation of overlapping peaks. Figure 7 illustrates this for two such pole figures $(101+011)$ and $(201+021)$. All these resolved recalculated pole figures are very similar again. Where 7 pole figures were used the separation relied on intensity difference in three overlapped pole figures (Figure $7 \mathrm{a}, \mathrm{b}, \mathrm{e}, \mathrm{f}$ ), where two pole figures were used it relies on single overlapped pole figure $(101+011)$. The trigonal symmetry is expressed in differences in pole figures betweeen positive and negative rhombs. It is also visible in ODF's. In the case of hexagonal symmetry sections at $0^{\circ}$ and $30^{\circ}$, 


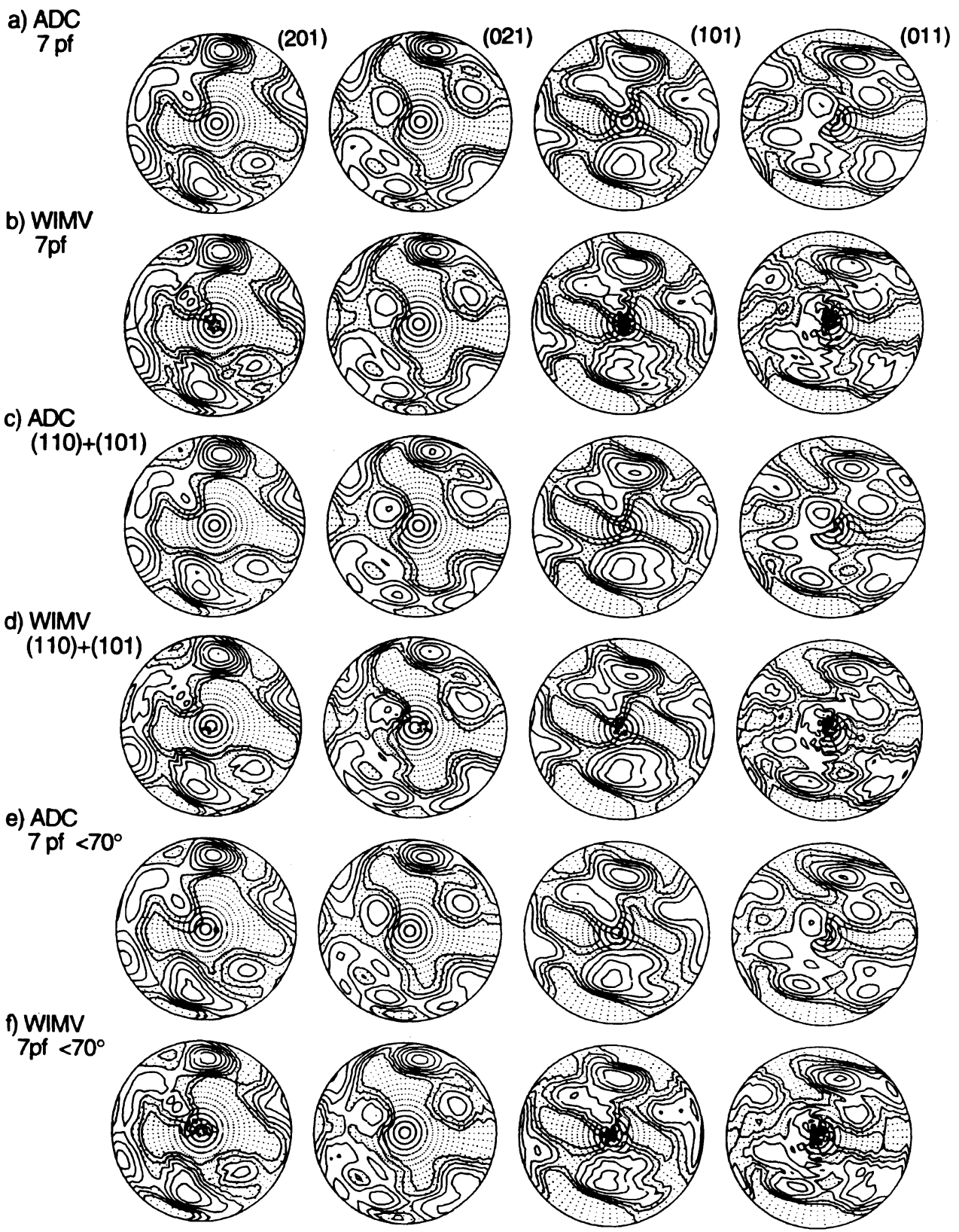

Figure 7 Recalculated pole figures of overlapping peaks of quartzite Brg 420. Logarithmic contours $(0.5,0.71,1,1.41,2$ etc.), dotted below 1 m.r.d.. 
Table 3 Numerical data for ODF calculation of quartzite Brg 420 (c.f. Figures 5, 6).

\begin{tabular}{|c|c|c|c|c|c|c|c|}
\hline \multirow[t]{2}{*}{ Method } & \multirow[t]{2}{*}{ Input } & \multirow{2}{*}{$\begin{array}{l}\text { Sum of hkl } \\
\text { Intersections }\end{array}$} & \multirow{2}{*}{$\begin{array}{c}\text { Texture } \\
\text { Index }\end{array}$} & \multicolumn{2}{|c|}{$O D F$ (m.r.d.) } & \multicolumn{2}{|c|}{ PF 001 (m.r.d.) } \\
\hline & & & & $\min$ & $\max$ & $\min$ & $\max$ \\
\hline $\begin{array}{l}\text { ADC } \\
\text { WIMV }\end{array}$ & $\begin{array}{l}7-90^{\circ} \\
7-90^{\circ}\end{array}$ & 36 & $\begin{array}{l}8.62 \\
8.20\end{array}$ & $\begin{array}{l}0.00 \\
0.01\end{array}$ & $\begin{array}{l}36.95 \\
36.13\end{array}$ & $\begin{array}{l}0.01 \\
0.01\end{array}$ & $\begin{array}{l}13.37 \\
13.35\end{array}$ \\
\hline $\begin{array}{l}\text { ADC } \\
\text { WIMV }\end{array}$ & $\begin{array}{l}2-90^{\circ} \\
2-90^{\circ}\end{array}$ & 9 & $\begin{array}{l}7.60 \\
7.44\end{array}$ & $\begin{array}{l}0.00 \\
0.01\end{array}$ & $\begin{array}{l}33.43 \\
39.43\end{array}$ & $\begin{array}{l}0.00 \\
0.01\end{array}$ & $\begin{array}{l}12.08 \\
12.01\end{array}$ \\
\hline $\begin{array}{l}\text { ADC } \\
\text { WIMV }\end{array}$ & $\begin{array}{l}7-70^{\circ} \\
7-70^{\circ}\end{array}$ & $22-30$ & $\begin{array}{l}7.64 \\
7.70\end{array}$ & $\begin{array}{l}0.00 \\
0.01\end{array}$ & $\begin{array}{l}40.65 \\
38.04\end{array}$ & $\begin{array}{l}0.04 \\
0.01\end{array}$ & $\begin{array}{l}13.16 \\
13.81\end{array}$ \\
\hline $\begin{array}{l}\text { ADC } \\
\text { WIMV } \\
\text { WIMV } \\
\text { smoothed }\end{array}$ & $\begin{array}{l}2-80^{\circ} \\
2-80^{\circ} \\
2-80^{\circ}\end{array}$ & $6-9$ & $\begin{array}{l}7.34 \\
7.68\end{array}$ & $\begin{array}{l}0.00 \\
0.01 \\
0.00\end{array}$ & $\begin{array}{l}35.90 \\
67.55 \\
35.49\end{array}$ & $\begin{array}{l}0.01 \\
0.01\end{array}$ & $\begin{array}{l}12.06 \\
12.65\end{array}$ \\
\hline
\end{tabular}

$10^{\circ}$ and $40^{\circ}, 20^{\circ}$ and $50^{\circ}$ would be identical. They are similar, but distinct differences confirm the trigonal symmetry of the texture. The orientations $\sigma$ and $\sigma+30^{\circ}$ are related by the Dauphiné twin law which has been documented in neighboring grains of $\mathrm{Brg}$ 420 by EBSP measurements (Kunze et al., 1994).

In Figures 8 and 9 we illustrate ADC derived ODF's and pole figures for Brg 420 based on a single complete pole figure as input. Lattice planes 110 and 112 have hexagonal symmetry and correspondingly ODF's are also hexagonal (section $\sigma$ and $\sigma+30^{\circ}$ afe identical, in Figure 8 the $30^{\circ}$ section is not shown) and positive and negative rhombs can not be separated. Using a complete 102 pole figure (consisting of overlapped 102 and 012 pole figures) the ODF (Figure 8c) is similar to that obtained for 7 complete pole figures (Figure 8a) although there are some artificial distortions (e.g. in the $\sigma=40^{\circ}$ section with a double maximum). If an incomplete 102 pole figure is used distortions are worse with an artificial arc (e.g. Figure $8 \mathrm{~d}, \sigma=20^{\circ}$ ). In the case of an incomplete 112 pole figure (used to $85^{\circ}$, Figure $8 \mathrm{f}$ ) the solution is very noisy with unacceptable artifacts. ODF's obtained with WIMV have similar properties, including artifacts. It is an interesting and so far undocumented property of discrete methods that for solutions with minimal data but within the MPDS criterion (Table 4) numerical artifacts are present.

The additional peaks and distortions in these ODF's are not true "ghosts" due to the lack of information from the odd (non-centric) functions. Ghosts are always weaker than the real texture maxima and they do not exist in pole figures. We have further verified this by expanding the WIMV Brg 420 texture (Figure 5b) with even and odd spherical harmonics, using the procedure described by Wenk et al. (1988) (Figure 10). While ghosts of considerable intensity (negative area in the odd expansion up to 4 m.r.d., Figure 10c) are present, they are at different positions. Notice that most, but not all ghost falsifications are associated with the true texture maxima. The additional peaks in Figure 8d, $\mathrm{f}$ are attributed to the vastly underdetermined system of equations and are introduced by the iteration procedure which always find a solution but not necessarily the correct one.

Most pole figures on Figure 9, corresponding to ODF's on Figure 8 agree well with experimental data (Figure 4a) and recalculated pole figures for the 7 pole figure solution (Figure 9a), even those which were not used as input. The largest deviations are in the pole figures obtained with 112 data to $85^{\circ}$ (Figure 9f). But recalculated pole figures reproduce those used as input very closely. 


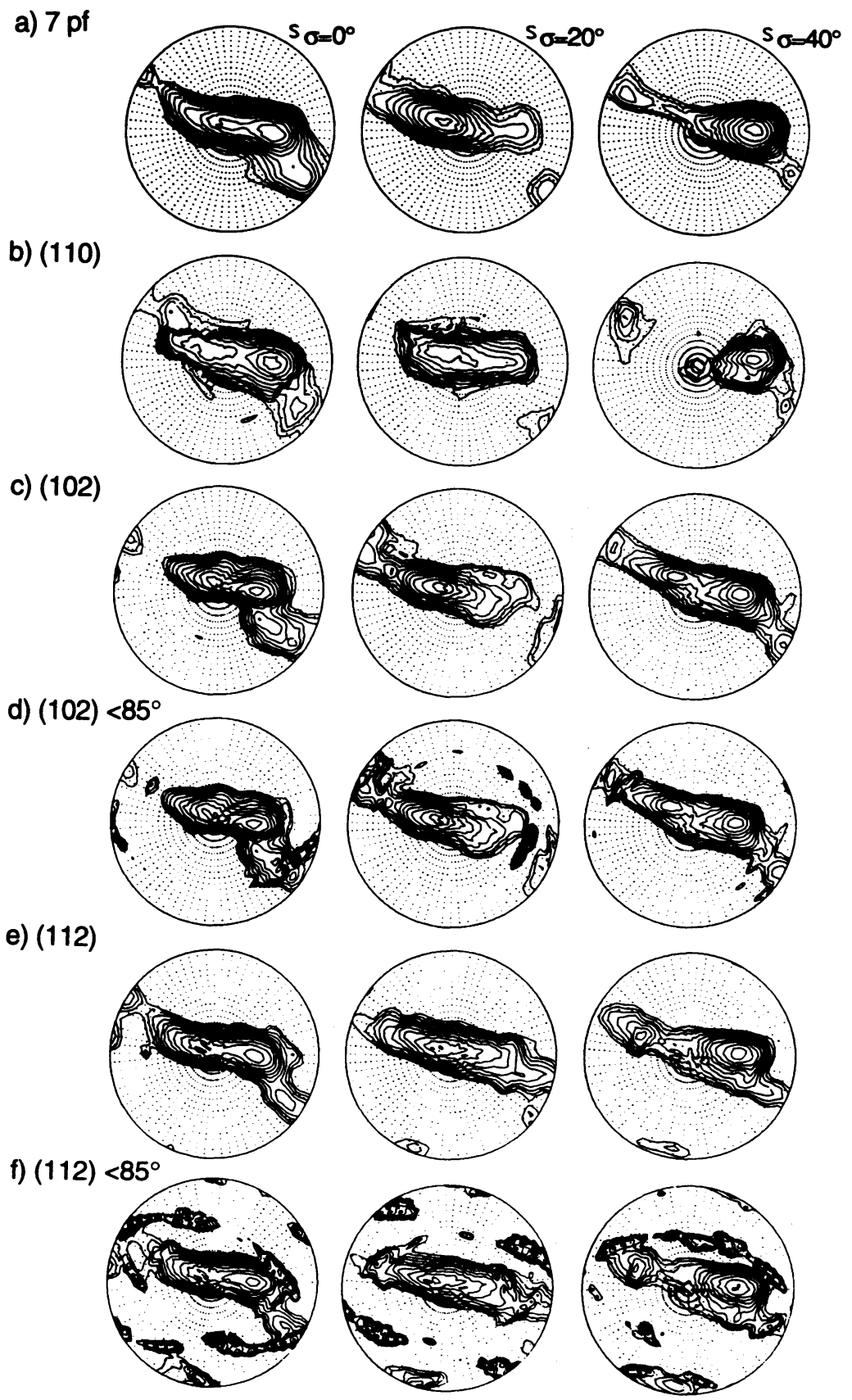

Figure 8 ODFs for quartzite Brg 420 represented as $\sigma$-sections. (a) 7 pole figure ADC solution, (b-f) single pole figure ADC solutions. Logarithmic contours $(0.5,0.71,1,1.41,2$ etc.), dotted below 1 m.r.d.. 
a) $7 \mathrm{pf}$

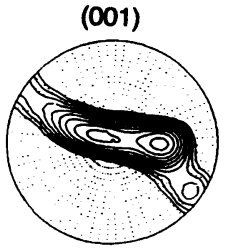

b) (110)

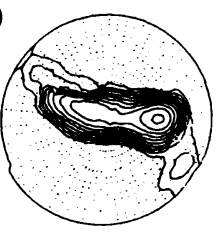

c) (102)

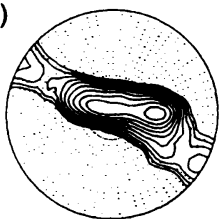

d) $(102)<85^{\circ}$

e) (112)
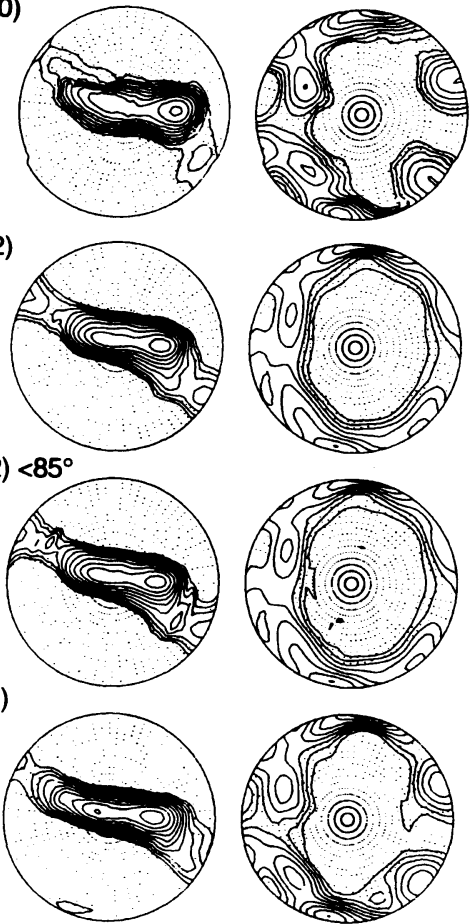

f) (112) $<85^{\circ}$
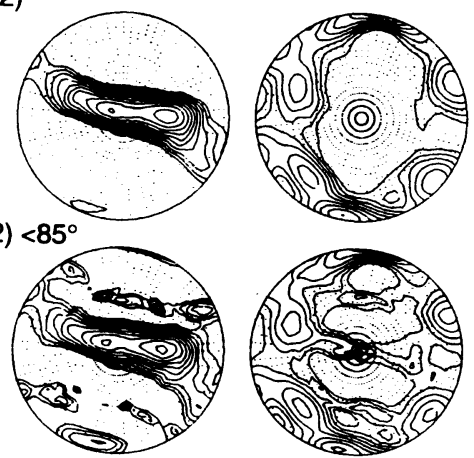
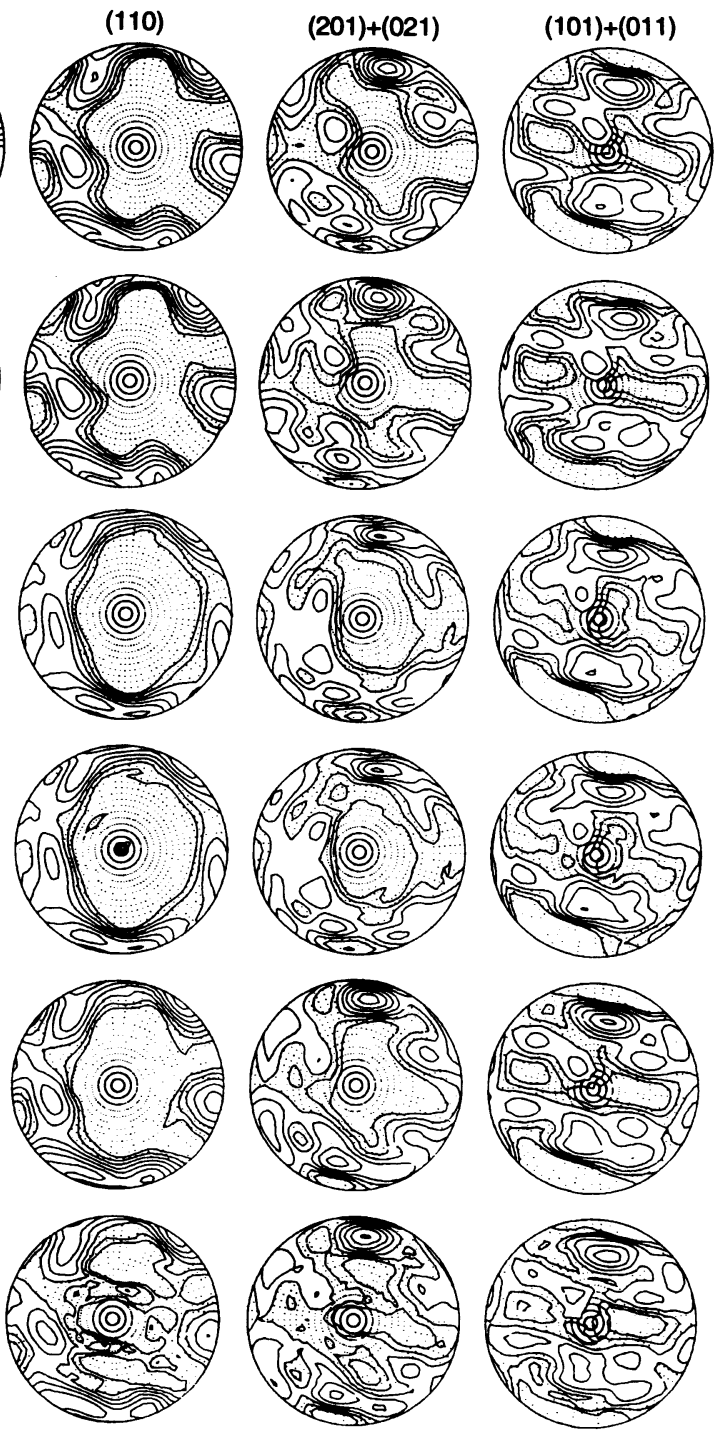

Figure 9 Pole figures of quartzite $\mathrm{Brg} 420$. (a) 7 pole figure ADC solution, (b-f) single pole figure ADC solutions. Logarithmic contours $(0.5,0.71,1,1.41,2$ etc.), dotted below 1 m.r.d..

The texture of $\mathrm{Brg} 420$ is strong and pole figures contain relatively large areas close to zero which eliminates considerable ambiguity from ODF calculations. We find that ADC and WIMV, even for minor details, approximate the same solution. Minor deviations in ODF's (Figure $5 \mathrm{e}, \mathrm{f}$ ) and major distortions in 1-pole figure solutions (Figure 8d, f) are not due to the inherent ghost ambiguity but to the high indeterminacy of the system of equations. We will explore the influence of data on ODF calculations with a second quartzite sample, Sci 490 , which has a weaker and more complex texture. 
Table 4 Numerical data for ODF calculations of quartzite from a single pole figure with the ADC method (c.f. Figures 8, 9, 11, 12).

\begin{tabular}{|c|c|c|c|c|c|c|c|c|c|c|c|}
\hline \multirow[b]{3}{*}{ Input } & \multirow{3}{*}{$\begin{array}{l}\text { Sum of } h k l \\
\text { intersections }\end{array}$} & \multicolumn{6}{|c|}{ Brg 420} & \multicolumn{4}{|c|}{ Sci 490} \\
\hline & & \multirow{2}{*}{$\begin{array}{c}\text { Texture } \\
\text { Index }\end{array}$} & \multicolumn{2}{|c|}{$O D F$} & \multicolumn{2}{|c|}{ PF 001} & \multirow{2}{*}{$\begin{array}{c}\text { Texture } \\
\text { Index }\end{array}$} & \multicolumn{2}{|c|}{$O D F$} & \multicolumn{2}{|c|}{ PF 001} \\
\hline & & & $\min$ & $\max$ & $\min$ & $\max$ & & $\min$ & $\max$ & $\min$ & $\max$ \\
\hline $7-90$ & 36 & 8.6 & 0.0 & 37.0 & 0.0 & 13.4 & 2.8 & 0.1 & 12.1 & 0.2 & 5.1 \\
\hline $110-90$ & 3 & 7.1 & 0.0 & 24.6 & 0.1 & 12.4 & 2.8 & 0.0 & 8.7 & 0.1 & 6.5 \\
\hline $102-90$ & 6 & 8.2 & 0.0 & 33.6 & 0.0 & 14.6 & 2.8 & 0.1 & 13.8 & 0.2 & 5.1 \\
\hline $102-85$ & 4-6 & 8.1 & 0.0 & 36.1 & 0.0 & 14.2 & 3.2 & 0.0 & 18.4 & 0.2 & 5.2 \\
\hline $112-90$ & 6 & 8.0 & 0.0 & 35.6 & 0.0 & 14.4 & 1.8 & 0.2 & 7.3 & 0.4 & 4.7 \\
\hline $112-85$ & $5-6$ & 7.6 & 0.0 & 27.0 & 0.0 & 12.8 & 1.8 & 0.2 & 8.3 & 0.4 & 4.8 \\
\hline
\end{tabular}

a) Sum

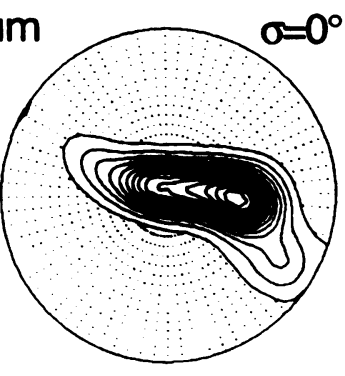

b) Even

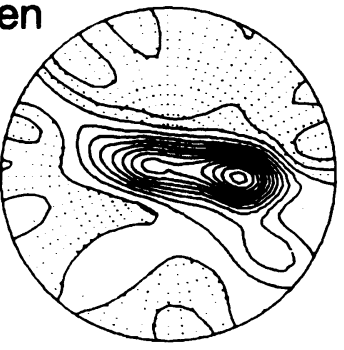

c) Odd

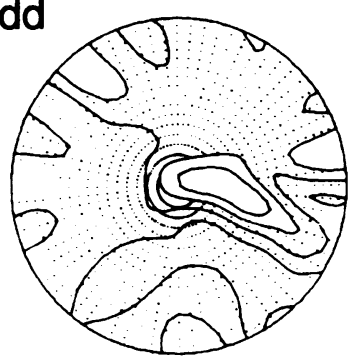

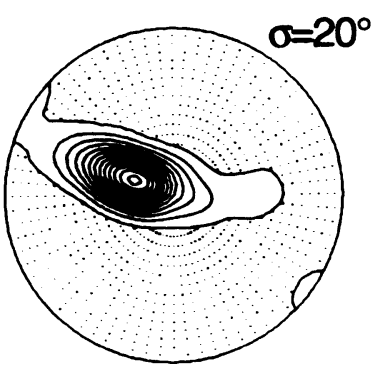
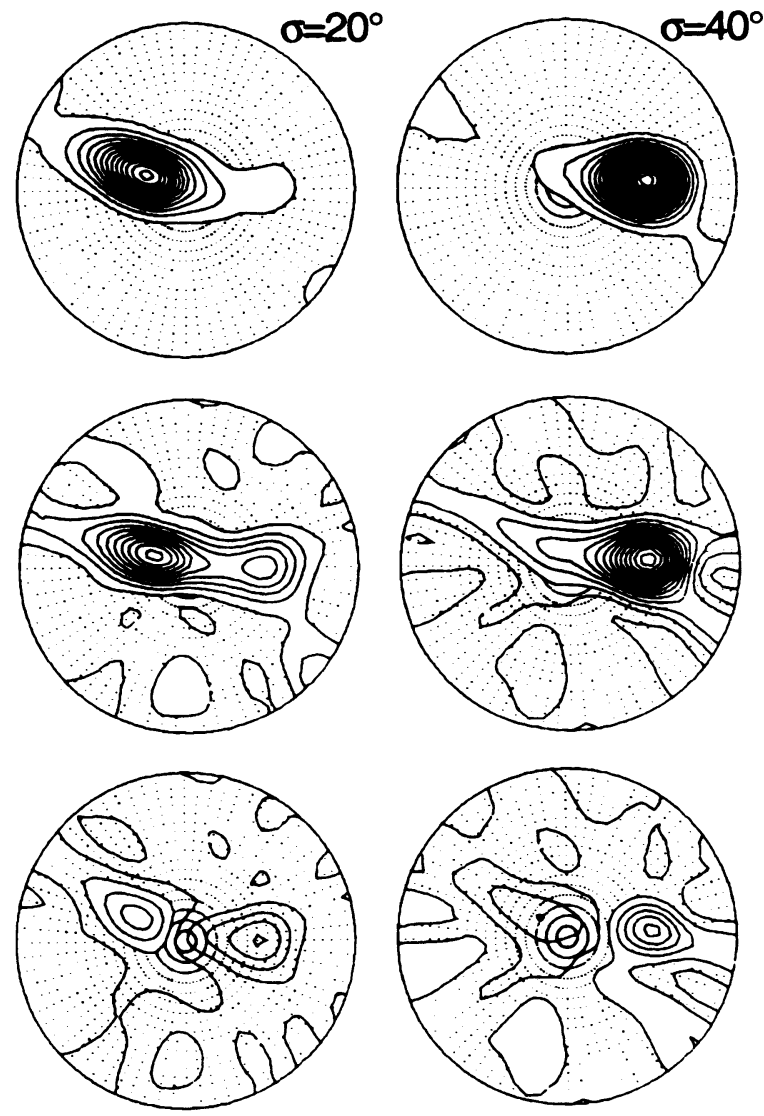

Figure 10 Harmonic expansion of WIMV seven pole figure ODF for $\mathrm{Brg} 420$ (Figure 5b), using (a) even and odd functions (maximum is 19.0 m.r.d., minimum 0 m.r.d.), (b) even functions (14.0 m.r.d./-1.8 m.r.d.) and (c) odd functions (6.0 m.r.d./-4.3 m.r.d.). "Ghosts" are best visible as negative regions in the odd expansion. Expansion to $l=22$. Contour interval is 1 m.r.d., negative regions are dotted. 
A seven pole figure solution (Figure 11a) is compared with one pole figure solutions (Figure $11 \mathrm{~b}-\mathrm{f}$ ). As in the case of Brg 420 there are visible falsifications in ODF's (Figure 11) and some recalculated pole figures which were not used as input (Figure 12). However, they are less apparent because of the weaker textures. Also with incomplete pole figure reproductions we obtained good results but there are variations in texture index and minimal and maximal values (Table 4). Naturally 110 and 112 produce hexagonal symmetry. The example illustrates that the reproduction is, as expected, highly texture dependent.

Finally we will explore a calcite sample where trigonal symmetry can be resolved without relying on intensity differences in overlapping peaks. The calcite texture is weak and also shows considerable complexity. In this case we illustrate mainly data for smoothed WIMV solutions but have done the same tests for ADC and obtained similar results. ODF's (Figure 13) and pole figures (Figure 14) display nearly orthorhombic sample symmetry, expressed by 2 -fold axes in corresponding oblique sections $20^{\circ}-40^{\circ}$ and mirror planes in $0^{\circ}$ and $30^{\circ}$ sections $\left(30^{\circ}\right.$ is not shown), and by mirror planes in the pole figures. Also visible in the ODF is the distinct trigonal symmetry, which is more pronounced in this calcite texture than in the two quartz textures and expressed in differences between $0^{\circ}$ and $30^{\circ}, 10^{\circ}$ and $40^{\circ}$ etc. sections. ODF's were calculated from 8,3 and 2 pole figures. In contrast to the quartz case we see in calcite at a first glance large differences between the models. The 3-pole figure model (Figure 13c, d) has a much weaker distribution than the 8 (Figure 13a, b) and the 2 pole figure model (Figure $13 \mathrm{e}, \mathrm{f}, \mathrm{g}$ ). In order to evaluate the quality of the reproductions one has to check recalculated pole figures for each case. The 8 pole figure models (Figure 14a, b) reproduce all pole figures adequately, except for 116 . Inspection of the experiment reveals that 116 is close and partially overlapped with 018 and indeed part of the pattern in the 116 pole figure must be the 018 pattern. Also the recalculated 202 pole figure is significantly weaker than the experimental one, suggesting perhaps an improper background substration. For neutrons 202 is a very weak diffraction peak (Wenk, 1991). For the 3 pole figure model we use the worst possible scenario and calculate the ODF from the weak reflection 202 and 116 with likely experimental errors due to overlaps and 113 for which measurements are reliable but the pole distribution is almost uniform. Even in this model 116, which served as input, can not be reproduced while 113 and 202 are adequate. The 2 pole figure model uses good experimental pole figures (110 and 104) but pole points are irregularly distributed in orientation space and their ranges are close to minimum of required hkl intersections (3) (Table 5). This also limits the resolution, particularly for a smooth texture with no zero regions and a high degree of inherent ambiguity. We find that ADC and WIMV solutions are again very similar but only WIMV solutions are shown.

\section{CONCLUSION AND RECOMMENDATIONS}

Naturally for these experimental textures we do not know the real ODF but we assume that the ODF which is based on the largest set of experimental data is closest to the real or "true" one. This is to some extent confirmed for Brg 420 by individual orientation measurements by EBSP which yield a practically identical ODF as that in Figure 4a (Kunze et al., 1994). We document with three examples that ODF solutions depend on the quantity and quality of experimental data but selection criteria rely critically on the texture type and not only on the crystallography. The solution may also depend 
a) $7 \mathrm{pf}$
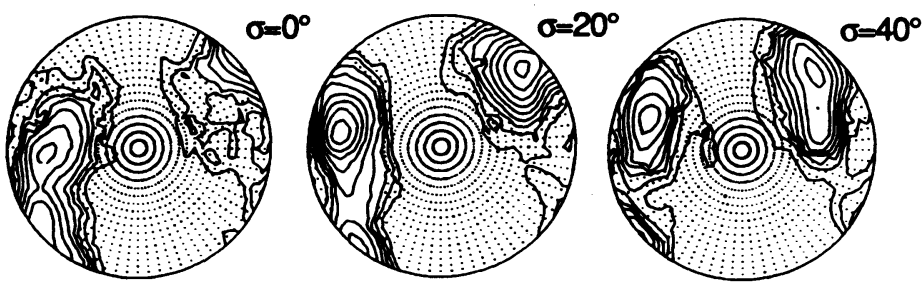

b) (110)
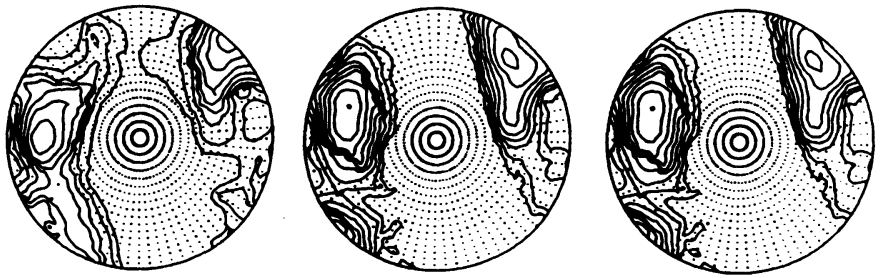

c) (102)
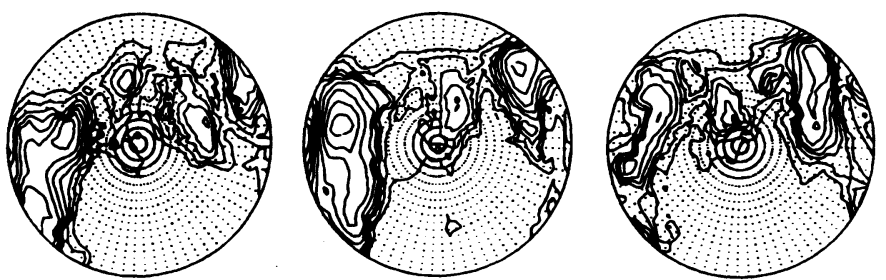

d) $(102)<85^{\circ}$
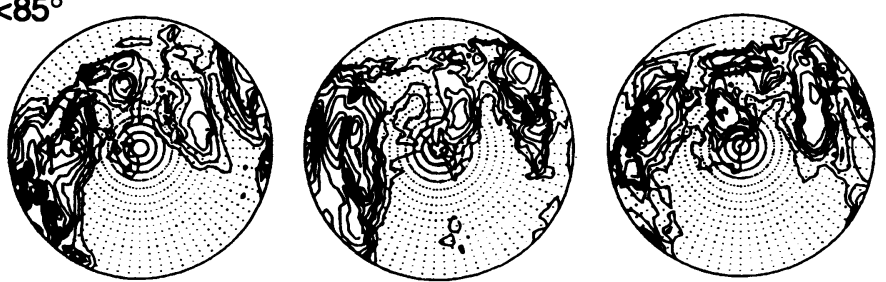

e) (112)
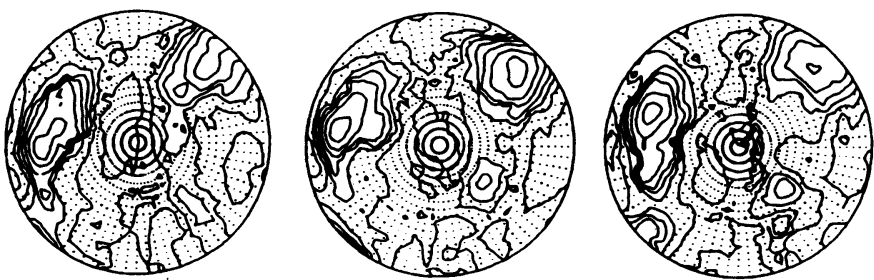

f) $(112)<85^{\circ}$

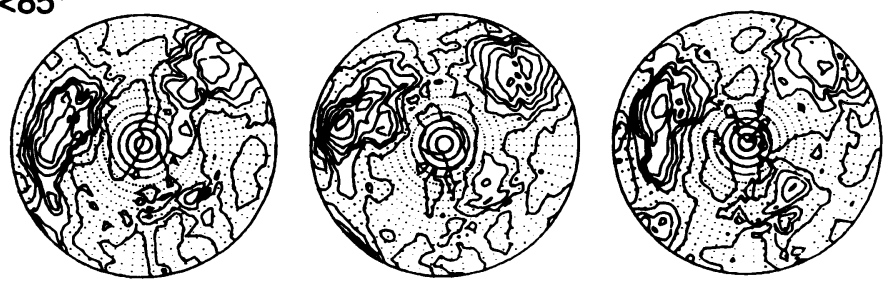

Figure 11 ODFs for quartzite Sci 490 represented as $\sigma$-sections. (a) 7 pole figure ADC solution, (b-f) one pole figure ADC solutions. Logarithmic contours $(0.5,0.71,1,1.41,2$ etc.), dotted below 1 m.r.d.. 


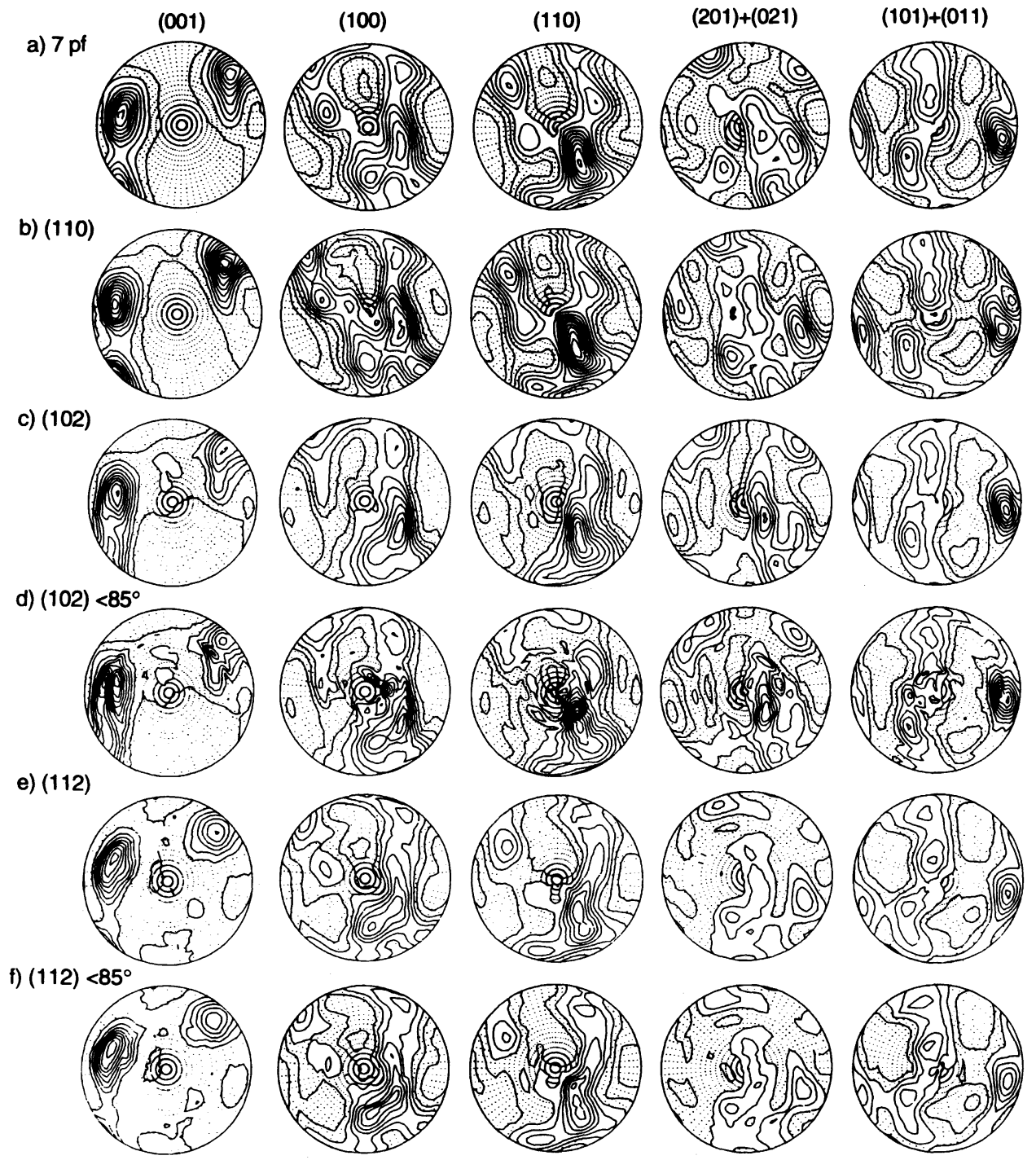

Figure 12 Pole figures of quartzite Sci 490. (a) 7 pole figure ADC solution, (b-f) one pole figure ADC solutions. Contour interval is 0.2 m.r.d. except for 001 where it is 0.5 m.r.d., dotted below 1 m.r.d..

on reproduction methods but we found very similar results for ADC and WIMV which is not surprising since both use similar algorithms. In detail WIMV provides the highest possible background (phon) distributing ghosts evenly over it. In the ADC the value of the ODF at a particular position is the highest possible. The minima at a point has the smallest value of any of the correponding pole figure projection fibres. In practice differences are small. ADC provides visually a smoother distribution as is expected from the more sophisticated integration but after post-analysis filtering WIMV results 
a) $8 \mathrm{pf}$

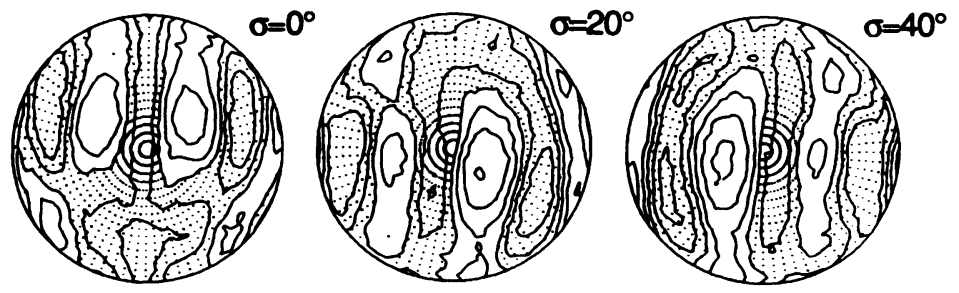

b) $8 \mathrm{pf}<70^{\circ}$

c) $113+116+202$
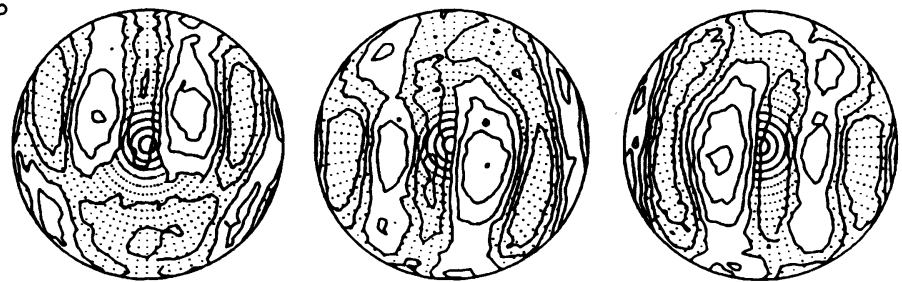

d) $113+116+201$
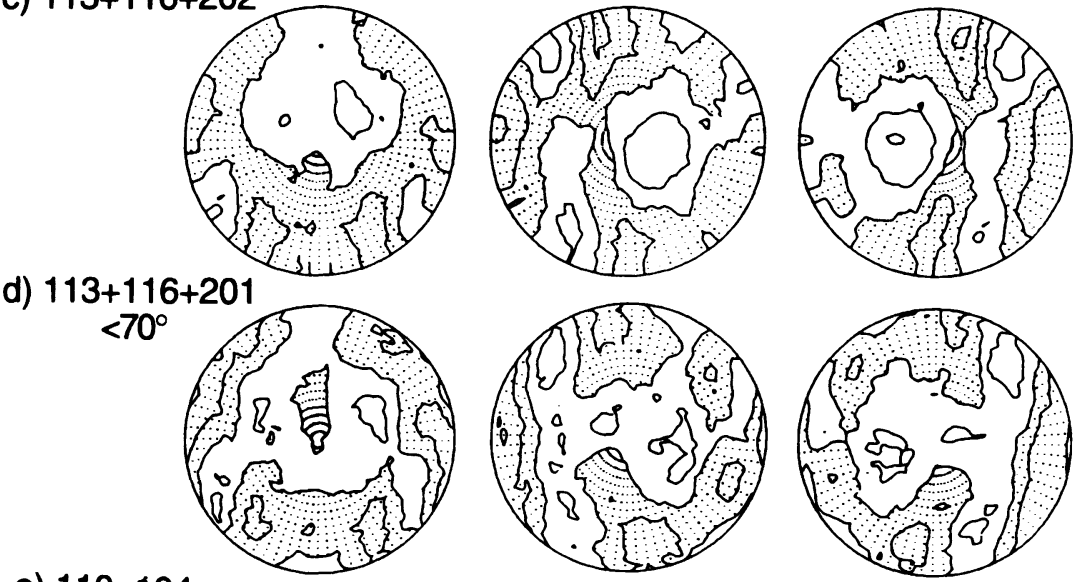

e) $110+104$
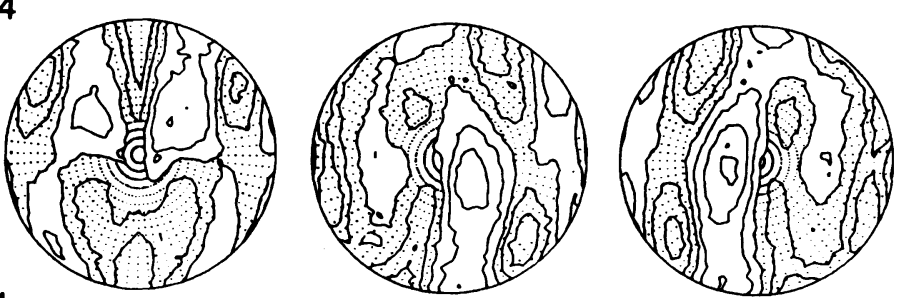

f) $\begin{array}{r}110+104 \\ <70^{\circ}\end{array}$

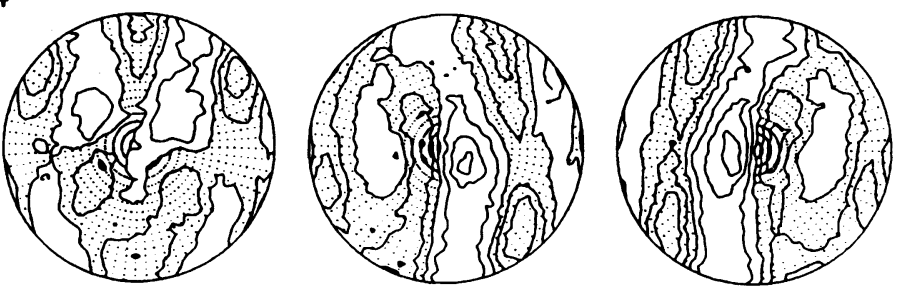

Figure 13 ODFs for experimentally deformed limestone Gre 433, represented as $\sigma$-sections. Logarithmic contours $(0.5,0.71,1,1.41,2$ etc.), dotted below 1 m.r.d.. 


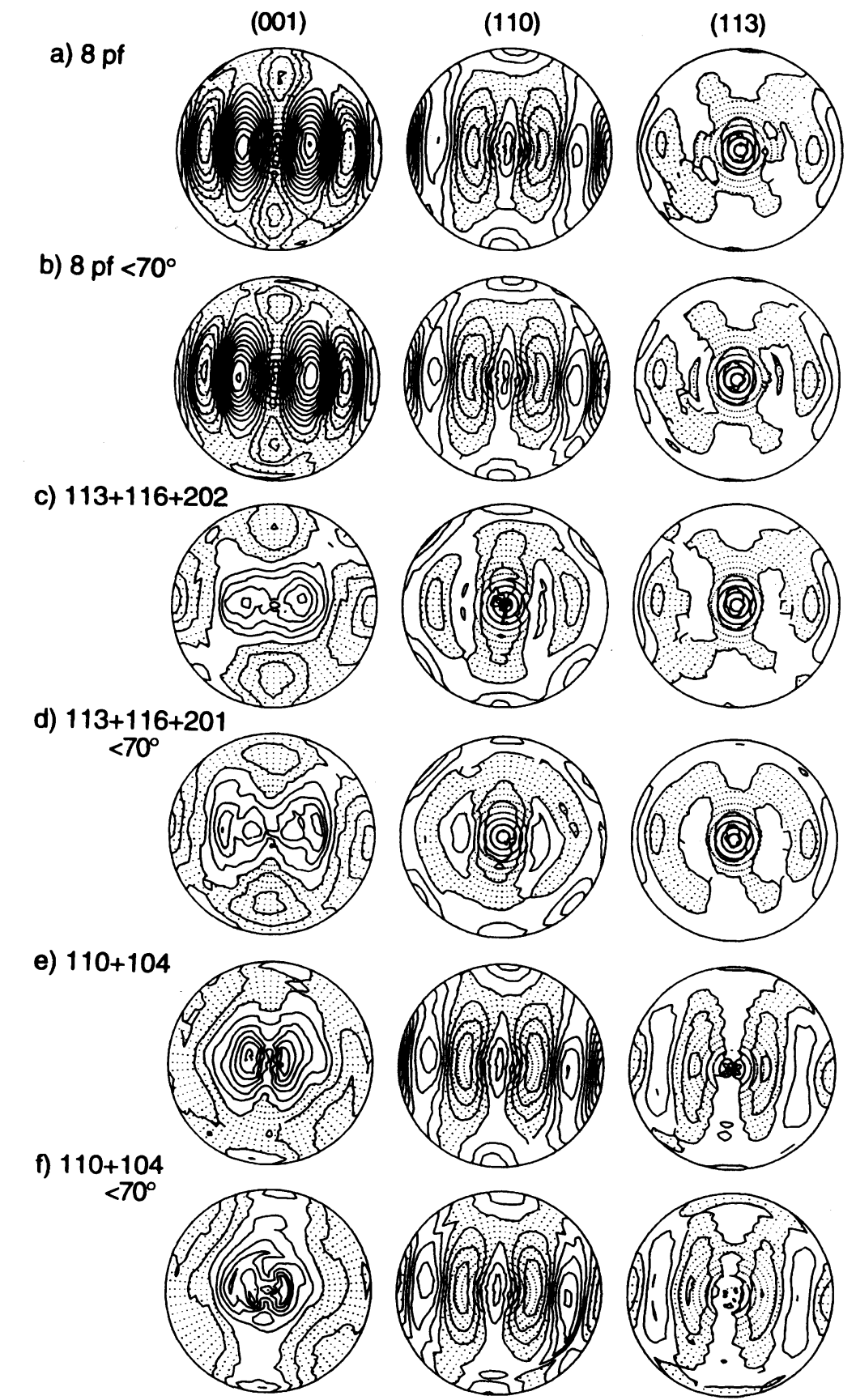

Fig. 14a

Figure 14 Pole figures of experimentally deformed limestone recalculated from the ODF for different models as indicated. Pole figure 012 which was used in the $\mathbf{8}$ pole figure reconstruction is not shown. Contour interval 0.1 m.r.d., dotted below 1 m.r.d.. 

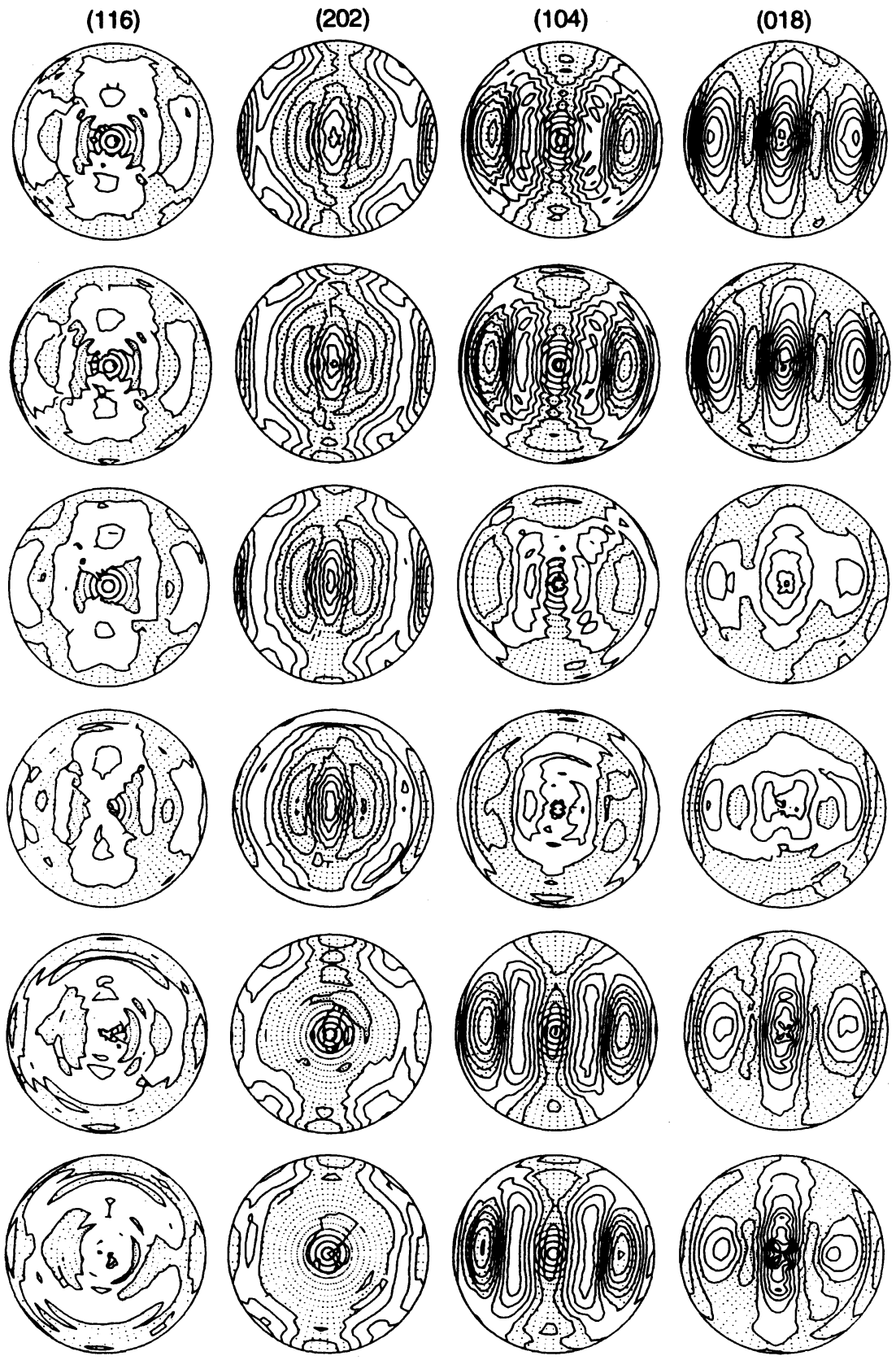

Fig. 14b 
Table 5 Numerical data for calcite ODF calculation, GRE 433 (c.f. Figures 13, 14).

\begin{tabular}{|c|c|c|c|c|c|c|c|}
\hline \multirow[t]{2}{*}{ Method } & \multirow[t]{2}{*}{ Input } & \multirow{2}{*}{$\begin{array}{l}\text { Sum of hkl } \\
\text { Intersections }\end{array}$} & \multirow{2}{*}{$\begin{array}{l}\text { Texture } \\
\text { Index }\end{array}$} & \multicolumn{2}{|c|}{$O D F$ (m.r.d.) } & \multicolumn{2}{|c|}{ PF 001 (m.r.d.) } \\
\hline & & & & $\min$ & $\max$ & $\min$ & $\max$ \\
\hline \multicolumn{2}{|c|}{ measured } & - & - & - & - & 0.30 & 2.01 \\
\hline $\begin{array}{l}\text { WIMV } \\
\text { ADC }\end{array}$ & $\begin{array}{l}8-90^{\circ} \\
8-90^{\circ}\end{array}$ & 28 & $\begin{array}{l}1.49 \\
1.29\end{array}$ & $\begin{array}{l}0.29 \\
0.22\end{array}$ & $\begin{array}{l}3.19 \\
3.90\end{array}$ & $\begin{array}{l}0.40 \\
0.32\end{array}$ & $\begin{array}{l}1.92 \\
1.98\end{array}$ \\
\hline $\begin{array}{l}\text { WIMV } \\
\text { ADC }\end{array}$ & $\begin{array}{l}8-70^{\circ} \\
8-70^{\circ}\end{array}$ & $17-23$ & $\begin{array}{l}1.25 \\
1.28\end{array}$ & $\begin{array}{l}0.26 \\
0.27\end{array}$ & $\begin{array}{l}3.18 \\
3.95\end{array}$ & $\begin{array}{l}0.37 \\
0.30\end{array}$ & $\begin{array}{l}1.92 \\
1.98\end{array}$ \\
\hline $\begin{array}{l}\text { WIMV } \\
\text { ADC }\end{array}$ & $\begin{array}{l}3-90^{\circ} \\
3-90^{\circ}\end{array}$ & 15 & $\begin{array}{l}1.08 \\
1.10\end{array}$ & $\begin{array}{l}0.38 \\
0.47\end{array}$ & $\begin{array}{l}2.22 \\
2.63\end{array}$ & $\begin{array}{l}0.59 \\
0.56\end{array}$ & $\begin{array}{l}1.52 \\
1.48\end{array}$ \\
\hline $\begin{array}{l}\text { WIMV } \\
\text { ADC }\end{array}$ & $\begin{array}{l}3-70^{\circ} \\
3-70^{\circ}\end{array}$ & $8-14$ & $\begin{array}{l}1.08 \\
1.05\end{array}$ & $\begin{array}{l}0.46 \\
0.63\end{array}$ & $\begin{array}{l}1.88 \\
2.11\end{array}$ & $\begin{array}{l}0.64 \\
0.71\end{array}$ & $\begin{array}{l}1.43 \\
1.48\end{array}$ \\
\hline $\begin{array}{l}\text { WIMV } \\
\text { ADC }\end{array}$ & $\begin{array}{l}2-90^{\circ} \\
2-90^{\circ}\end{array}$ & 6 & $\begin{array}{l}1.19 \\
1.33\end{array}$ & $\begin{array}{l}0.28 \\
0.14\end{array}$ & $\begin{array}{l}3.13 \\
4.46\end{array}$ & $\begin{array}{l}0.51 \\
0.47\end{array}$ & $\begin{array}{l}1.69 \\
2.16\end{array}$ \\
\hline $\begin{array}{l}\text { WIMV } \\
\text { ADC }\end{array}$ & $\begin{array}{l}2-70^{\circ} \\
2-70^{\circ}\end{array}$ & $3-6$ & $\begin{array}{l}1.19 \\
1.24\end{array}$ & $\begin{array}{l}0.32 \\
0.36\end{array}$ & $\begin{array}{l}4.06 \\
3.08\end{array}$ & $\begin{array}{l}0.49 \\
0.47\end{array}$ & $\begin{array}{l}1.81 \\
1.77\end{array}$ \\
\hline
\end{tabular}

for these samples become almost identical. Refined integration comes with the cost of more extensive programming and computer time even though the latter is minimal. The choice will be largely based on availability. With both methods overlapped pole figures can be separated into individual pole figures with different pole distributions.

In comparing the data from different samples and different models several general features emerged which not only apply to ODF reconstructions with the ADC and WIMV methods. We summarize them as recommendations:

- It is useful to rely on as much experimental data as possible. ODF reconstructions are more reliable and it is possible to identify pole figures with experimental errors (e.g. by comparing RP error values for individual pole figures). Those pole figures can be rejected and the ODF can be recalculated without them.

- If one has the choice, it is more efficient to rely on fewer complete pole figures than on a larger number of incomplete pole figures, but this is often not possible.

- Pole figures with sharp topography are more informative than smooth distributions which are close to uniform. The pole multiplicity plays a role. In principle a high multiplicity is more informative but pole figures with strong density variations the angular distance between symmetrically equivalent poles must be high.

- Take into account the quality of the diffraction spectrum. Avoid pole figures from weak diffraction peaks and partially overlapped peaks.

- In choosing a set of pole figures consideration should be given to a fairly uniform pole distribution on the orientation sphere. This is best evaluated by plotting poles of used diffraction peaks in inverse pole figures (Figure 2).

- The minimum condition of three $h k l$ intersections in all ODF cells must be met but satisfactory resolution generally requires a pole multiplicity ("legs") of at least 6 per cell. The available number for a given set of pole figures and the corresponding measured region should be evaluated.

- In choosing pole figures, crystal symmetry must be considered. In the case of quartz only overlapping peaks with different intensity contributions can resolve the trigonal symmetry. The symmetry to be resolved must be present in the experimental data. 
A lattice plane 110 only resolves hexagonal symmetry and a 001 pole figure with a single direction can not determine an orientation. For example it is not possible to resolve the orthorhombic symmetry of a pseudotetragonal materials unless different h00 and 0k0 distributions are recorded.

On the whole we have been surprised by the small amount of data necessary to obtain a satisfactory resolution in these low symmetry materials. Analysis with 4 pole figures measured to $70^{\circ}$ proved to be adequate in most cases. Such pole figures can be easily obtained by X-ray diffraction, and one does not need to rely on the availability of neutrons for measuring complete pole figures. Similarly, it can be argued that small pole figure sectors (e.g. over a pole distance range from $0^{\circ}$ to $30^{\circ}$ ) would be sufficient if ten pole figures are used. This is significant for neutron diffraction where available time is restricted and only limited ranges can be measured, but at the same time position sensitive detectors or time-of-flight systems may be available enabling one to measure a spectrum with many pole figures simultaneously (Wenk et al., 1994).

\section{Acknowledgements}

We are appreciative for constructive reviews by $\mathrm{S}$. Matthies and $\mathrm{H}$. Bunge and financial support through NSF grants EAR 90-17237 and INT 89-21295, IGPP-LANL, the University of California Energy Program and the Polish Academy of Sciences.

\section{References}

1. Baker, D. W., Wenk, H.-R. and Christie, J. M. (1969). J. Geol., 77, 143-172.

2. Baker, D. W. and Wenk, H.-R. (1972). J. Geol., 80, 81-105.

3. Berthé, D., Choukroune, P. and Jegouzo, P. (1979). J. Struct. Geol., 1, 31-42.

4. Bunge, H.-J. and Wenk, H.-R. (1977). Tectonophysics, 40, 257-285.

5. Bunge, H.-J. (1982). Texture Analysis in Materials Science; Butterworths, London.

6. Dahms, M. (1993). Textures and Microstructures, 21, 61-69.

7. Helming, K. (1991). Textures and Microstructures, 14-18, 187-192.

8. Helming, K., Matthies, S. and Vinel, G. W. (1988). Proc. 8th. Int. Conf. on Textures, ASM, p. 55-60.

9. Helming, K., Wenk, H.-R., Choi, C. S. and Schäfer, W. (1994). In "Textures in Geological Materials". Deutsche Ges. Metalkunde, Oberursel. (in press).

10. Imhof, J. (1978). Proc. Sth. Int. Conf. on Textures, Springer Verlag, Vol. 1, 149-157.

11. Imhof, J. (1982). Textures and Microstructures, 5, 73-86.

12. Ivankina, T., Nikitin, A. N., Voitus, W. and Walther, K. (1991). Textures and Microstructures, 14-18, 421-429.

13. Jura, J., Pospiech, J. and Mazur, A. (1978). Krist. Technik, 13, 303-309.

14. Kallend, J. S., Kocks, U. F., Rollett, A. D. and Wenk, H.-R. (1991). Mat. Sci. and Engin, A132, $1-11$.

15. Kallend, J. S., Schwarz, R. B. and Rollett, A. D. (1991). Textures and Microstructures, 13, 189-197.

16. Kunze, K., Adams, B. L., Heidelbach, F. and Wenk, H.-R. (1994). Proc. 10th Int. Conf. on Textures of Materials, (in press).

17. Mancktelow, N. S. (1987). Tectonophysics, 135, 133.

18. Matthies, S. (1979). Phys. Status Solidi (b), 92, 135-138.

19. Matthies, S. (1980). Crystal Research and Technology, 16, 1061-1071.

20. Matthies, S. (1991). Textures and Microstructures, 14-18, 1-12.

21. Matthies, S., Helming, K. and Kunze, K. (1990a). Phys. Status Solidi (b), 157, 71-83.

22. Matthies, S., Helming, K. and Kunze, K. (1990b). Phys. Status Solidi (b), 157, 489-507.

23. Matthies, S. and Vinel, G. W. (1982). Phys. Status Solidi (b), 112, K111-120.

24. Matthies, S. and Wenk, H.-R. (1992). Phys. Status Solidi (a), 133, 253-257.

25. Matthies, S., Wenk, H.-R. and Vinel, G. W. (1988). J. Applied Cryst., 21, 285-304.

26. Pawlik, K. (1986). Phys. Status Solidi (b), 134, 477-483. 
27. Pawlik, K. (1992). Proc. 2-nd Europ. Powder Diffr. Conf., 151-156. Enschede, The Netherlands.

28. Pawlik, K., Pospiech, J. and Lücke, K. (1991). Textures and Microstructures, 14-18, 25-30.

29. Pospiech, J. (1988a). Bull. Pol. Acad. Sci., 36, 49-59.

30. Pospiech, J. (1988b). Proc. 8th. Int. Conf. on Textures, ASM, 93-114.

31. Ruer, D. and Baro, R. (1977). Adv. X-ray Analysis, 20, 187-200.

32. Sander, B. (1950). Einführung in die Gefügekunde der geologischen Körper. Vol. 2, 399 p., Springer Verlag.

33. Schäben, H. (1988). J. Applied Physics, 64, 2236.

34. Schäfer, W., Jansen, E., Merz, P., Will, G. and Wenk, H.-R. (1992). Physica B, 180-181, $1035-1038$.

35. Schmid, S. M. and Casey, M. (1986). Amer. Geophys. U., Geophys. Monogr., 38, 263-286.

36. Trommsdorff, V. and Wenk, E. (1963). Schweiz. Mineral. Petrogr. Mitt., 43, 687-700.

37 Vadon, A. (1981). Généralisation et Optimisation de la Méthode Vectorielle d'Analyse de la Texture. These d Etat. Metz University., 298 p.

38. Van Houtte, P. (1983). Textures and Microstructures, 6, 1-20.

39. Wang, F., Xu, J. and Liang, Z. (1988). Proc. 8th. Int. Conf. Texture, ASM, 111-114.

40. Wang, F., Xu, J. and Liang, Z. (1989). Textures and Microstructures, 10, 217-226.

41. Wenk. H.-R. (1985). In: "Preferred Orientation in Deformed Metals and Rocks", pp. 11-47. Academic Press, Orlando, FL.

42. Wenk. H.-R. (1991). J. Appl. Cryst., 24, 920-927.

43. Wenk, H.-R., Johnson, G. C. and Matthies, S. (1988). J. Appl. Phys., 63, 2876-2879.

44. Wenk, H. R., Matthies, S. and Lutterotti, L. (1994). Proc. 10th Int. Conf. on Textures of Materials, (in press).

45. Williams, R. O. (1968). J. Appl. Phys., 39, 4329-4335. 